W. V. Harlow, CFA

Keith C. Brown, CFA

\title{
The Role of Risk Tolerance in the Asset Allocation Process: \\ A New Perspective
}

The Research Foundation of

The Institute of Chartered Financial Analysts 


\section{The Research Foundation of The Institute of Chartered Financial Analysts}

\section{Board of Trustees}

\author{
Chairman \\ James R. Vertin, CFA \\ Alpine Counselors \\ Vice Chairman \\ George W. Noyes, CFA \\ Standish, Ayer \& Wood, Inc. \\ Research Director \\ Charles A. D'Ambrosio, CFA \\ University of Washington

\section{President \\ Alfred C. Morley, CFA \\ Association for Investment \\ Management and Research \\ Darwin M. Bayston, CFA \\ Association for Investment Management and Research \\ Thomas A Bowman, CFA
Association for Investment
Management and Research}

Gerald O. Bierwag

University of Arizona

Charles A. D'Ambrosio, CFA

University of Washington

Joanne M. Hill

PaineWebber, Inc.

Alfred C. Morley, CFA

President

Darwin M. Bayston, CFA Executive Vice President
Gary P. Brinson, CFA

Brinson Partners, Inc.

Charles D. Ellis, CFA

Greenwich Associates

Frederick L. Muller, CFA

Atlanta Capital Management

William F. Sharpe

Sharpe-Tint, Inc.

Eugene C. Sit, CFA

Sit Investment Associates, Inc.

Walter P. Stern, CFA

Capital Research Co.

Donald L. Tuttle, CFA

Indiana University

\section{Review Board}

\author{
Mark P. Kritzman, CFA \\ Windham Capital Management \\ Richard Roll \\ UCLA \\ Roll \& Ross Asset Management \\ Gary G. Schlarbaum, CFA \\ Miller, Anderson \& Sherrerd
}

\section{Officers}

\author{
Thomas A. Bowman, CFA \\ Senior Vice President
}

Katrina F. Sherrerd Vice President 
(C) 1990 The Research Foundation of the Institute of Chartered Financial Analysts

All rights reserved. No part of this publication may be reproduced, stored in a retrieval system, or transmitted, in any form or by any means, electronic, mechanical, photocopying, recording, or otherwise, without the prior written permission of the copyright holder.

This publication is designed to provide accurate and authoritative information in regard to the subject matter covered. It is sold with the understanding that the publisher is not engaged in rendering legal, accounting, or other professional service. If legal advice other expert assistance is required, the services of a competent professional should be sought.

From a Declaration of Principles jointly adopted by a Committee of the American Bar Association and a Committee of Publishers.

ISBN 10-digit: 0-943205-04-2 ISBN 13-digit: 978-0-943205-04-5

Printed in the United States of America

Joni L. Tomal, Editor

Susan S. Brennan, Production Editor

Diane B. Hamshar, Administrative Assistant

Nina D. Hutchinson, Typography/Layout 


\section{Mission}

The mission of the Research Foundation is to identify, fund, and publish research material that:

- expands the body of relevant and useful knowledge available to practitioners;

- assists practitioners in understanding and applying this knowledge; and

- enhances the investment management community's effectiveness in serving clients.

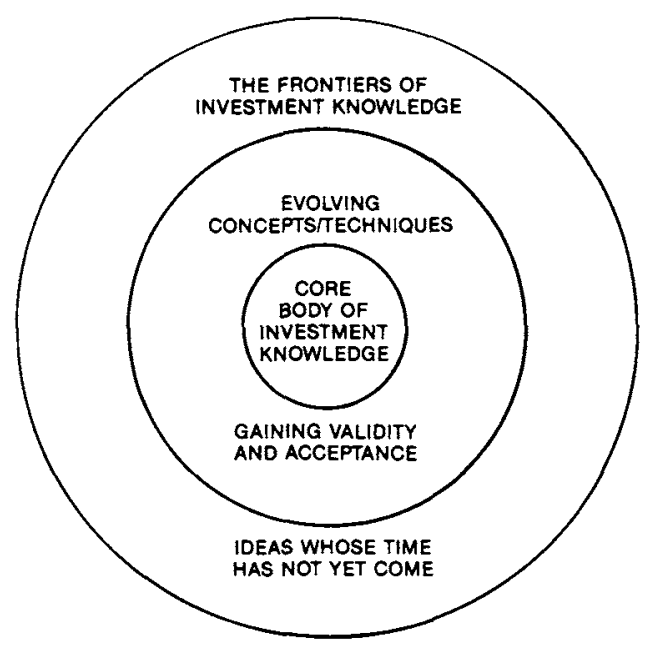

The Research Foundation of

The Institute of Chartered Financial Analysts

P.O. Box 3668

Charlottesville, Vinginia 22903 


\section{Table of Contents}

Acknowledgements $\ldots \ldots \ldots \ldots \ldots \ldots$ ix Foreword $\ldots \ldots \ldots \ldots \ldots \ldots \ldots \ldots \ldots \ldots$ Introduction $\ldots \ldots \ldots \ldots \ldots \ldots \ldots \ldots \ldots$ xiii

Chapter 1. Investor Financial Risk Tolerance . . . . . . . . 1 Chapter 2. Experimental Measures of Risk Aversion . . . . . . . 13 Chapter 3. A New Perspective of Risk Aversion . . . . . . . 23 Chapter 4. Summary and Implications . . . . . . . . . . 45 Appendixes

A. First Price Sealed Bid Auction . . . . . . . . . 49

B. Lottery Pair Instructions . . . . . . . . . . . . 51

C. Second Price Auction Instructions $\ldots \ldots \ldots$

References . . . . . . . . . . . . . . . . . 57 


\section{ACKNOWLEDGEMENTS}

Financial support for this project was graciously provided by the Research Foundation of the Institute of Chartered Financial Analysts, the University of Arizona Foundation (grant program of the Office of the Vice President for Research), and the Economic Science Laboratory at the University of Arizona. The authors would especially like to thank Charles D'Ambrosio for support and encouragement on this project.

The opinions and analyses presented herein are those of the authors and do not necessarily represent the views of Salomon Brothers Inc, the Research Foundation of the Institute of Chartered Financial Analysts, or the University of Arizona Foundation. This research was conducted while the first author was at the College of Business and Public Administration at the University of Arizona.

W. V. Harlow, CFA

Salomon Brothers Inc

Keith C. Brown, CFA The University of Texas at Austin 


\section{FOREWORD}

How do we know what investors feel, and how those feelings are measured?

This study addresses these questions from an intriguing new angle by exploring ideas that are on the outer edge of the Institute's body of knowledge. The subject matter introduces concepts which are not now widely understood but should gain validity and acceptance in the investment community over time. Consider the following excerpt:

Specifically, we have shown that for our subject group, individuals with neurochemical activity characterized by lower levels of the enzyme monoamine oxidase tended to be more willing to accept economic risk. Conversely, higher levels of this enzyme appeared to be associated with more risk-averse behavior.

These startling and potent results have wide-ranging consequences and suggest that this auspiciously begun research path will quickly find itself entering the core set of material available to investment practitioners. Indeed, the Harlow and Brown results are so beguiling that forward-looking investment professionals will find the way, no doubt tentatively at first, to incorporate the results of this inquiry into their practice.

We all know that an investor's risk preferences should dominate asset allocation decisions, the desired goal being "to locate oneself on the market line" by determining the proper balance of risk and expected return, given how one feels about those trade-offs. To date, we have not been able to determine what investors feel and how those feelings are measured. The tentative answers to those questions have been murkily qualitative and, in many ways, heavily dependent on psychology. So, whereas we acknowledge the importance of risk aversion to wise long-run decisions, we must also recognize that we know very little about how to assess it so systematically and intelligently that the risk aversion of the client, not that of the portfolio manager or analyst, is definitely used.

Harlow and Brown fill some of the void by the novel approach of focusing on biologically measurable traits to assess client risk aversion. They study the information given off by neurotransmitters-secretions of chemical substances by neuronal fiber terminals which produce electrical impulses that are processed from cell to cell. Concomitantly, they establish that quantifiable risk 
aversion is in the realm of the possible. They guide us through a risk-aversion determination process that is quick, to the point, and rigorous. Although much more needs to be done, this study is a promising launching on the heavy, largely unchartered seas of risk-aversion analysis. The Research Foundation is delighted to fund such innovative, thought-provoking work.

Charles A. D'Ambrosio, CFA The Research Foundation of the Institute of Chartered Financial Analysts 


\section{INTRODUCTION}

In the quest for superior performance, portfolio managers have traditionally focused much of their attention on methods for selecting individual securities. A survey of the literature oriented toward these professionals over the past two decades reveals an inordinate emphasis on the role of the appropriate valuation model. More recently, however, there has been a noticeable shift in the perspective adopted by the money management community. Specifically, the allocation of funds among the various asset classes (e.g., equities, fixed income, real estate) is finding an important place in the portfolio formation process. Much of this renewed interest in the role of the asset allocation decision may be attributed to modern portfolio theory, which suggests that markets are sufficiently precise in the setting of prices to mitigate the potential for achieving consistently abnormal returns on individual security investments. Brinson, Hood, and Beebower (1986) provide substantive empirical support for this recent trend by demonstrating that over 93 percent of the return performance in the typical investment portfolio may be attributed to the initial allocation decision (as opposed to market timing or security selection decisions).

As Sharpe (1987) has defined it, the asset allocation process calls for the analysis of two distinct sets of informational inputs. First, the portfolio manager must be able to quantify accurately expectations about current economic conditions and their effects on capital market prices. A critical step in evaluating these data is the ability to translate general forecasts into specific predictions about the expected returns, risks, and correlations across the universe of relevant assets.

Second, the performance expectations and risk tolerance of the investor must also be assessed as accurately as possible prior to the formation of investment recommendations. In contrast to the market-wide considerations required in the first step, an analysis of this set of inputs requires the manager to consider information specific to the needs of the individual or institutional client. Once these disparate sources of information have been summarized separately, they may be integrated to determine the appropriate asset mix for the investor in question. The ability to create an effective balance in this integration process is often what defines the successful portfolio manager.

Whereas the basic approach outlined above may be viewed as a stylistic model for all asset allocation procedures currently used, there is nevertheless 
a lack of unanimity on the manner in which some of the informational components are generated. More precisely, of the two sets of variables, there is general agreement about the information required to develop the capital market inputs. Although the exact methods used to obtain ex ante estimates of asset returns, risk, and correlations may vary among managers, there is concurrence about the definitions of the measures themselves. Conversely, there appears to be little agreement about either the operational form or the measurement of financial risk tolerance on any level. Despite the general agreement among investment professionals that clients are best regarded as risk averse (though not necessarily to the same degree), a consistent method of quantifying such preferences has yet to be established. What has been developed instead is a vast array of ad hoc procedures for imparting economic meaning to perceived investor behavior. Of course, this apparently haphazard approach to measuring risk aversion is hardly an indictment of the money management community. Rather, it mirrors a more pervasive lack of understanding about how individuals behave in uncertain economic settings. Consequently, in view of its importance in the asset allocation process, a more thorough examination of the nature of financial risk tolerance is merited.

The purpose of this study is twofold. First, we review what is presently known about investor preferences and assess some of the methods currently employed by portfolio managers to approximate client risk tolerances. Second, we discuss some recent developments in the area of experimental economics that provide important insights into the formation of economic preferences and risk aversion and may ultimately lead to improved asset allocation techniques. The intended benefit of such an investigation is the development of a formal means of tying an investor's innate attitudes toward risk-bearing to a more exact measure of risk tolerance that may be included in the portfolio formation process. Along these lines, our primary focus is to identify some of the factors underlying an individual's economic decisionmaking. In particular, we demonstrate that there is a significant relation between certain psychological and biological characteristics and empirically derived measures of risk aversion. It is hoped that introducing these linkages will allow money managers to develop a deeper appreciation for the unique aspects of this undeniably important part of their investment activities.

This study is organized as follows. In Chapter 1 the precise role of risk tolerance in the asset allocation decision is reviewed. This discussion will include a consideration of theoretical models of the trade-off between risk and 
the return required by investors, as well as a summary of what is currently known about the risk preferences of individuals. An assessment of existing methods for quantifying economic behavior is included at this point. In Chapter 2, an experimental economic approach to investigating individual preferences is motivated and explicit measures of risk aversion are developed. In this context, experimental economics involves the use of controlled laboratory auction markets to elicit economically tractable responses from individuals and, hence, infer differences in the tolerance of financial risk. In Chapter 3 , an exploration of the possible determinants of these experimental measures is presented. Specifically, a biochemical and psychological basis for differences in economic behavior across individuals is developed and some preliminary evidence is presented in support of such a connection. Finally, Chapter 4 contains a discussion of the applicability of this study to current investment management practices as well as the implications it has for future research. 


\section{Investor Financial Risk Tolerance}

\section{Investor Return-Risk Objectives}

As noted earlier, Sharpe (1987) characterizes the asset allocation process as an integration of two distinct sets of information. The first set of required inputs-the capital market variables-establishes the expected return-risk opportunities available to all investors, whereas the second-the risk tolerance function-designates the asset mixes preferred by an individual investor. For the portfolio manager faced with the task of allocating funds for a specific portfolio, this process may be viewed sequentially in Figures 1 and 2 . Figure 1 depicts the efficient frontier which, for the set of available individual securities, is the collection of portfolios offering the greatest level of expected return for a given level of risk. This set of optimal portfolios summarizes the expectational information contained in the capital market variables.

To illustrate the implied trade-offs available to the portfolio manager, consider portfolios P1 and P2. Without loss of generality, assume P1 represents the "low-risk" mixture of equity and fixed-income securities (e.g., 20 percent stocks and 80 percent bonds) whereas $\mathrm{P} 2$ is the "high-risk" mixture (e.g., 80 percent stocks and 20 percent bonds). Either of these portfolios represents asset allocations that could be appropriate for an individual client, so the selection of a specific portfolio depends on the level of the investor's financial risk tolerance. For example, consider two investors (A and B) who have different attitudes about the permissible level of uncertainty in their portfolios. From Figure 1, it is apparent that to be able to select the optimal portfolio for each investor, it is necessary to translate each investor's risk tolerance into an explicit statement about the amount of expected return demanded for a given level of risk. Standard utility theory suggests that this 
may be accomplished for the individual investor through the development of a series of indifference curves, which summarize the combinations of risk and expected return that provide an equal amount of satisfaction (i.e., utility). Thus, the integration of the capital market and investor risk-tolerance variables requires that investors strive to achieve their greatest possible welfare given the currently available set of investment alternatives.

\section{FIGURE 1}

\section{Efficient Return-Risk Opportunity Set Available to Investors}

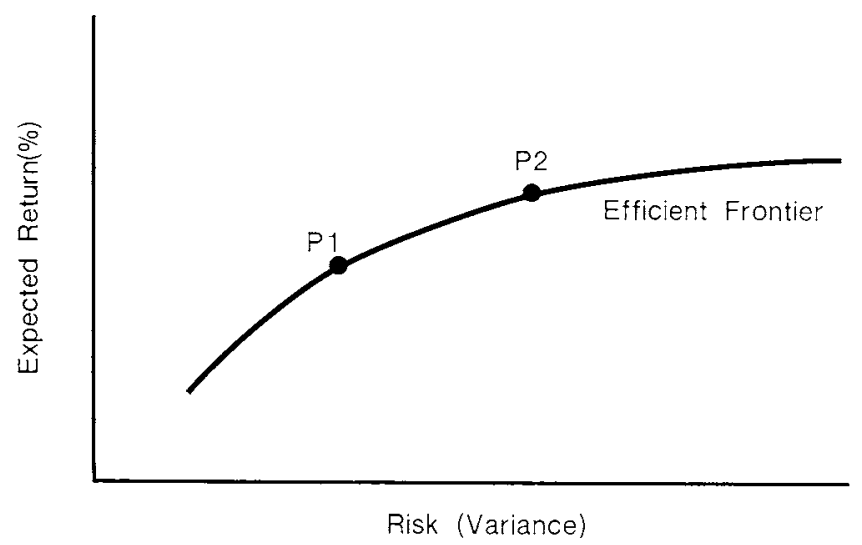

Figure 2 illustrates the result of this process. In this display, investors A and $B$ are represented by indifference curves that slope upward to the right. This is consistent with the notion of risk aversion. That is, these investors require successively larger amounts of expected return for bearing more risk. Further, it is also clear from an inspection of Figure 2 that client A demands a much larger return for a given increment of risk than does client $B$. This conclusion may be inferred from the fact that, whereas both investors' indifference curves have the same general shape, A's is far more steeply sloped. In this sense, individual A may be regarded as more risk averse than individual $B$. It is the combination of individual-specific and market-wide information that allows the money manager to select the appropriate asset allocation for each investor (portfolios P1 and P2 for clients A and B, respectively).

Figure 2 is also instructive because it emphasizes the importance of the assumptions that the portfolio manager must make in deciding upon the 
proper asset mix for different clients. Regardless of the ultimate preferences of any particular investor, the efficient frontier of investment possibilities is common to allocations involving the same initial universe of assets. Although the estimation of this frontier is by no means a trivial matter (see, for example, Markowitz 1959), it is nevertheless possible with existing statistical techniques and market data. Thus, the uniqueness of the allocation decisions appropriate for different investors rests entirely with the assumed level of risk tolerance. This factor also creates the greatest potential for imprecision. Clearly, in Figure 2, the assigned portfolios are separated only by the varying degrees of risk aversion of investors $\mathrm{A}$ and $\mathrm{B}$. This tolerance for investment uncertainty must be ascertained by the portfolio manager. The ultimate allocation decision depends, however, on what often amounts to an educated guess. Consequently, a deeper understanding of risk aversion and its measurement is a logical place to focus attention in the hope of improving the consistency of the asset allocation process.

But first recall that analytically three types of investors are identifiable: (1) risk averse-those who prefer certain outcomes today to uncertain ones in the future; (2) risk neutral-those who are indifferent between certain outcomes today and future uncertain outcomes; and (3) risk seeking-those who prefer the uncertain outcomes of the future to the certain ones of today. The commonplace assumption is that investors are risk averse.

Two other major constructs of the study are: (1) more wealth is preferred to less; that is, the utility of incrementally larger doses of wealth is positive; and (2) the utility of each successive dose of wealth is less than the prior ones. These core concepts give rise to two additional notions important to investment managers, namely absolute risk aversion and relative risk aversion. Absolute risk aversion (ARA) states that there is an absolute aversion to risk, no matter what, and that investors at the same wealth level may be characterized according to their individual risk aversions. The higher ARA is, the more risk averse an investor is. Relative risk aversion (RRA) measures an investor's risk aversion relative to his particular wealth level.

Most analysts assume that investors have decreasing absolute risk aversion and a constant relative risk aversion, which is to say that required risk premiums decrease through time and as wealth increases. Each of the riskaverse conditions may be specified more formally. The following section does just that (one may safely skip it without losing continuity of thought). 


\section{FIGURE 2}

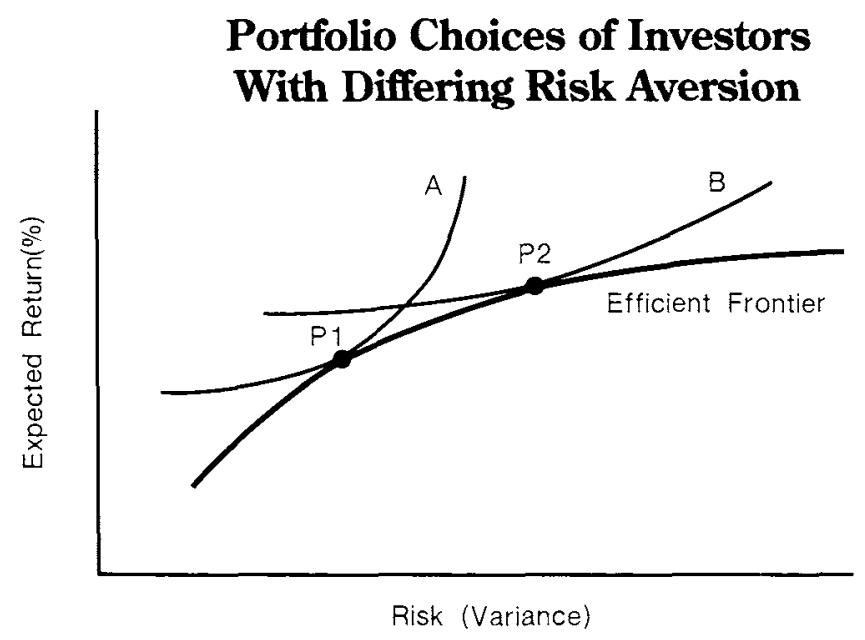

\section{Measures of Risk Aversion ${ }^{1}$}

As shown in the preceding discussion, the measurement of risk aversion may be directly tied to the measurement of an investor's utility function. The advantage of this linkage is that by focusing on the expected utility associated with a potential investment, instead of just its expected return, it is possible to summarize the risk preferences of an investor far more accurately. Such a process, as Markowitz (1959: 208) noted, also avoids any "hedonistic interpretation" of the investor's implicit trade-off between risk and expected return. Further, the expected utility approach will make it possible to quantify several explicit measures of risk tolerance, such as a coefficient indicating the investor's degree of risk aversion, as well as the return premium that would serve as sufficient compensation for risk bearing.

To establish these connections more formally, consider a representative investor having a utility function, $u(w)$, which translates the amount of wealth possessed into a level of personal satisfaction. An investment that potentially could improve or deteriorate that investor's current economic situation (depending, of course, on whether it is successful) may be viewed in two ways. First, the investor may consider the investment's expected payoff, $\mathrm{E}(\mathrm{w})$, and the level of utility associated with this amount, $\mathrm{u}[\mathrm{E}(\mathrm{w})]$. This approach is

${ }^{1}$ This section formally specifies risk-averse conditions. Readers may skip to the next section without losing continuity of thought. 
equivalent to focusing on the amount of satisfaction that could be achieved if the actuarial value of the investment was received with certainty. Alternatively, the investment's expected utility, $\mathrm{E}[\mathrm{u}(\mathrm{w})]$, could be computed. A comparison of these two statistics generates the following definitions:

$\mathrm{u}[\mathrm{E}(\mathrm{w})]>\mathrm{E}[\mathrm{u}(\mathrm{w})]$ denotes risk aversion;

$\mathrm{u}[\mathrm{E}(\mathrm{w})]=\mathrm{E}[\mathrm{u}(\mathrm{w})]$ denotes risk neutrality;

$\mathrm{u}[\mathrm{E}(\mathrm{w})]<\mathrm{E}[\mathrm{u}(\mathrm{w})]$ denotes risk seeking.

That (1a) implies risk aversion is best seen by recognizing that, if this inequality holds, our investor will obtain greater utility from a certain investment $(\mathrm{u}[\mathrm{E}(\mathrm{w})])$ than the utility expected from taking the risky one $(\mathrm{E}[\mathrm{u}(\mathrm{w})])$. On the other hand, if the presence of uncertainty is preferred, then the investor is said to be risk-seeking (equation (1c)), whereas indifference implies risk neutrality (equation (1b)). A concave (convex, linear) utility function is sufficient to ensure risk aversion (risk seeking, risk neutrality).

As discussed earlier, it is generally assumed that investors are risk averse. In the present context, therefore, this is equivalent to assuming that they may be represented by concave utility functions. To create a meaningful representation of behavior, however, it must also be assumed that an investor's level of satisfaction continuously increases with successive additions to wealth. There are two ramifications that result from this type of mathematical characterization. First, the marginal utility of wealth is positive. This implies that investors, irrespective of risk preference, always prefer more wealth to less. Second, for risk-averse investors, each successive increment of wealth will add less satisfaction than did the last. In other words, the investor's marginal utility for wealth, although always positive, will decrease with each additional unit.

From the condition established by (1a), it is clear that the degree of risk aversion depends on the extent to which the level of satisfaction achieved with a certain investment exceeds that expected from the risky venture. Put differently, the risk-averse investor should be willing to accept a lesser guaranteed amount of expected wealth, $\mathrm{E}(\mathrm{w})$, in lieu of the uncertain investment. This amount is called the certainty equivalent (CE) of the investment. Accordingly, the value expressed by $[\mathrm{E}(\mathrm{w})-\mathrm{CE}]$ may be thought of as the premium that the risk-averse investor is willing to pay to avoid the uncertain investment altogether. Pratt (1964) and Arrow (1971) have shown that this risk premium, $\pi$, may be expressed in terms of the utility function as follows: 


$$
\pi=0.5 \sigma^{2}\left[\frac{-u^{\prime \prime}(w)}{u^{\prime}(w)}\right]
$$

where $\sigma^{2}$ denotes the variance of the payoffs associated with the uncertain investment. The right-hand side of equation (2) separates the relevant risk characteristics of the investment (i.e., $\sigma^{2}$ ) from the bracketed term, which summarizes investor-specific risk attitudes.

There are two measures of risk aversion associated with equation (2). The first, absolute risk aversion (ARA), is given by:

$$
\operatorname{ARA}=\frac{-u^{\prime \prime}(w)}{u^{\prime}(w)}
$$

and calculates the degree of risk aversion for a particular level of wealth. This is often called the Pratt-Arrow measure of risk aversion. It allows, at least conceptually, for a direct comparison of two different investors' attitudes toward risk. Specifically, the individual with the larger level of ARA is said to be the more risk averse in that a larger risk premium will be attached to the uncertain investment. The second measure, which assesses the investor's relative risk aversion (RRA), may be written:

$$
\operatorname{RRA}=\frac{-w u^{\prime \prime}(w)}{u^{\prime}(w)}
$$

where RRA may be viewed as an adjustment to ARA in that it attempts to express aversion toward the risky investment in proportion to the investor's overall level of wealth. To maintain a constant coefficient of RRA, the required risk premium must decrease as the wealth level of the investor increases. This, in turn, implies that ARA must be decreasing. Utility functions that have decreasing ARA and constant RRA are often used to represent the behavior of the "typical" investor. ${ }^{2}$

As an example of how these measures are computed, consider the specification of a utility function having the form $u(w)=(w)^{r}$, where $r$ is a constant. The respective first and second derivatives of this expression are

\footnotetext{
${ }^{2}$ See Ross (1981) and Machina and Neilson (1987) for other characterizations of risk aversion for expected utility maximizers.
} 
$u^{\prime}(w)=r(w)^{r-1}$ and $u^{\prime \prime}(w)=r(r-1)(w)^{r-2}$. For this functional form to be a valid representation of a risk-averse investor, the first condition outlined above (i.e., $\left.u^{\prime}(w)>0\right)$ requires that $r>0$, whereas the second (i.e., $u^{\prime \prime}(w)<0$ ) demands that $r<1$. From these calculations, it is easily confirmed that ARA $=(w)^{-1}(1$ $-r)$ and $R R A=(1-r)$. As $r$ changes, the levels of both ARA and RRA change inversely. It is in this sense that $r$ may be regarded as the measure of risk aversion for power utility functions. Finally, because their first derivatives with respect to wealth are negative and zero, ARA and RRA are decreasing and constant, respectively. This specification is consistent with the work of Friend and Blume (1975) and will be employed later in our consideration of risk tolerance in the asset allocation process.

\section{Cross-Sectional Characteristics of Investor Risk Tolerance}

Before examining a few of the specific techniques employed by portfolio managers to assess the risk tolerance of their clients, it is useful to consider some general demographic evidence on the subject. In particular, several researchers over the past decade have developed survey methodologies in an attempt to define cross-sectional differences in both the attitudes of individual investors and the portfolios they hold. As Baker and Haslem (1977) have defined it, the objectives of these studies “... are twofold: (1) to isolate the underlying factors that cause investors to vary in their perceptions of the desirability of specific common stocks; and (2) to see if these factors are systematically related to their socioeconomic and behavioral characteristics" (p. 1256). Although the approaches have differed across studies, the common thread that runs through all of them is that they tend to concentrate on readily observable physical and economic attributes rather than less easily obtained psychological ones. In this regard, variables such as age, marital status, wealth, and gender are often used to classify individuals into well-defined groups. Once these subgroups have been established, investor risk tolerance is inferred for a particular strata by examining the estimated volatility of the "aggregate," or composite, portfolio. In addition to the work of Baker and Haslem, typical examples of this line of research include Blume and Friend (1978) and McInish (1982).

Perhaps the most common cross-sectional difference uncovered by these investigations is that age and sex are significantly correlated with observable levels of portfolio risk. More exactly, both Baker and Haslem and Blume and Friend found that males were more willing to accept financial risk than were 
females. Further, Blume and Friend and McInish established a strong negative relation between age and the risk levels of the portfolios held by the investor. Accordingly, then, it appears that the tolerance to financial risk is quite possibly a dynamic characteristic throughout the life of an investor and may also be a function of other factors (such as gender). Clearly, this type of aggregate information is useful to the portfolio manager to some extent. What cannot be obtained from these surveys, however, is a sense of the heterogeneity of investor preferences within a given group. For example, can it be assumed that all 40-year-old males or females are willing to bear the same level of investment uncertainty? A far more specialized characterization of investor preferences would be necessary to answer this question satisfactorily. Of course, such individualized insights may only be ascertained through direct interaction between the portfolio manager and the client.

\section{Risk-Tolerance Assessment Procedures}

Given that few investment professionals would question the importance of being able to ascertain their clients' attitudes toward risk, it is surprising to find an almost total absence of unanimity about the proper assessment method. In fact, even a cursory inspection of the literature indicates that this area is seldom addressed with the same degree of rigor as is the analysis of the capital market side of the asset allocation equation. Generally speaking, existing risk-tolerance estimation techniques may be classified as being either formal or informal, depending on whether an attempt is made to quantify risk aversion explicitly or whether this assessment is done on an ad hoc basis. Typically, the substantive difference between these two approaches rests with the decision on the extent to which individual-specific characteristics are considered. A brief summary of representative methods of both varieties follows.

As a group, the risk-tolerance assessment methods that we classify as being informal rely primarily on the classification of investors on the basis of readily observable demographic or psychological traits. Included with this set are those asset allocation procedures that attempt to summarize risk tolerance by examining where the investor is in his or her lifetime planning horizon. All other things being equal, longer horizons dictate riskier asset allocations. Such an allocation procedure is based, in part, on what Milne (1983) has referred to as the "life cycle" of economic preferences in which risk aversion increases with age. An advantage of the life cycle assumption is that it is fully consistent with the cross-sectional relation between age and observed invest- 
ment risk discussed earlier. Once again, though, there is nothing in this approach that allows the portfolio manager to distinguish between the riskbearing propensities of two otherwise unique clients at the same point in their planning horizons. This point is amplified by Quattlebaum (1987), who argues that it is also necessary to consider the uncertainty of an individual's occupational status when determining the optimal asset mix.

A different approach within the informal class of assessment procedures has concentrated on the development of simple psychological profiles of the individual investor. Invariably, this plan of attack has involved the classification of certain personality traits developed from the responses given to questionnaires and interviews. The implicit assumption in these efforts is that such measurable psychometric variables are indeed related to the underlying economic preferences of the individual. Of course, it is difficult to measure the efficacy of this presumption because the informal approach, by design, moves directly from personality classification to asset allocation decision making. For example, Kaiser (1987) advocates the use of an investor personality classification system wherein a client's personality is scaled along two axes: "careful-impetuous" and "confident-anxious." The resulting stratification enables the client's portfolio to be diversified into different asset mixes. In a similar fashion, Lipper and Busby (1987) espouse the use of a multi-part questionnaire to assess the client's investment expectations and "temperature" for holding risky assets. Further, Droms (1987) has developed a "portfolio allocation scoring system" which makes a more direct translation of clientgenerated data from seven broad questions about investment objectives into a specific portfolio allocation decision. LeBaron, Farrelly, and Gula (1989) extend this surveying approach by soliciting both financial and "visceral" (e.g., willpower, anxiety) data from clients. Finally, Barnewall (1987) has noted the connection between an individual's psychological profile and his or her occupation. Specifically, after classifying her clientele into "active" and "passive" investors, she argues that affluent investors of similar professions should not be viewed as having homogeneous investment needs.

Unlike the somewhat loose characterizations outlined above, a more formal approach to the assessment of risk tolerance depends on the specification of an exact form for the investor's utility function. Once an explicitly mathematical form for investor satisfaction is selected, the asset allocation decision becomes a more mechanical operation. An example of this sort of functional representation is the approach used by Fouse (1982) and Condon 
(1982), who developed a utility function from the investor's designation of two threshold returns and a risk ratio capturing the marginal utility above and below these two thresholds. Figure 3 shows an example of this process. The optimal asset allocation then becomes the portfolio that maximizes the expected utility of the investor. A variation on this theme is provided by Fielitz and Muller (1983), who require investors to select a single target rate of return and one of three levels of risk aversion. These two variables are then used in conjunction with an assumed form of the utility function to generate a mathematical determination of the appropriate asset mix.

\section{FIGURE 3}

\section{Representation of an Investor's Utility for Various Levels of Return}

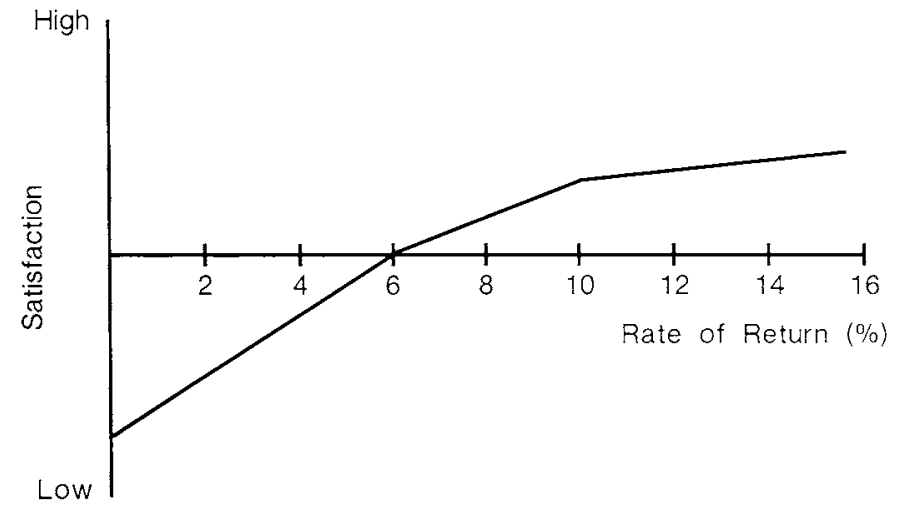

A logical extension of the utility-based approaches described above is one in which the portfolio manager elicits from the investor a direct specification of his or her preferred asset allocation. As Condon (1983) points out, however, an intelligent selection may only be made if the client is fully informed about the potential financial consequences of a given allocation. To assist the investor in making such a choice, the portfolio manager may provide a summary of various types of data defining the probabilistic outcomes of different capital market decisions. For example, Figure 4 defines the probabilities of failing to achieve alternative return goals as a function of the percentage of equity selected in a simple equity/fixed-income portfolio. Although it may seem to be an end in itself, this technique may also be used to infer the risk tolerance of the investor. As Sharpe (1987) has explained, this 
additional information may be useful for short-term tactical portfolio rebalancing as market conditions change. Starting with the assumption that investors exhibit constant absolute risk aversion, he demonstrates how a risk-aversion parameter may be estimated by the investor's specification of an asset mix. This parameter defines the investor far more completely than would any situation-specific responses. The obvious advantage of this extension is that it enables the portfolio manager to maintain an optimal portfolio on a more dynamic basis.

\section{FIGURE 4}

\section{Probabilities of Not Achieving Different Target Rates of Return as a Function of Asset Allocation}

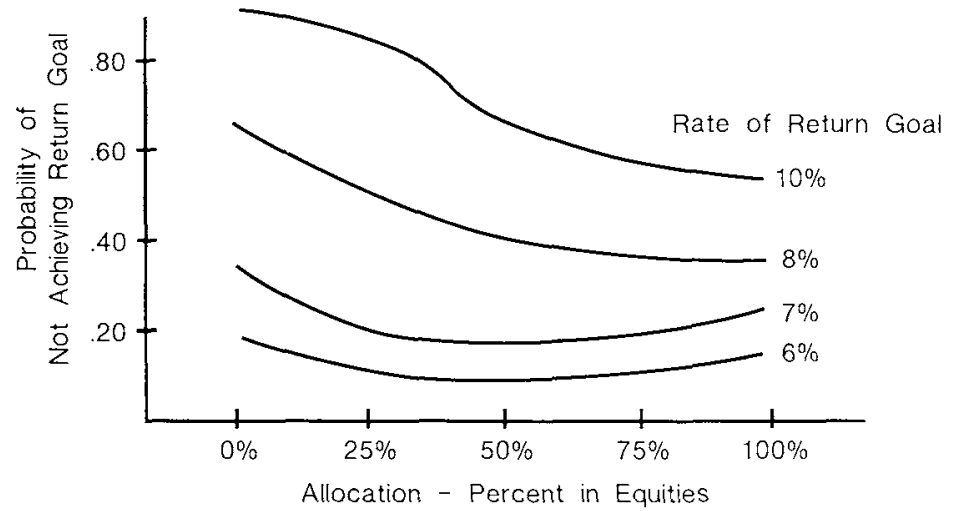

Although all of the research just cited is of great potential value as a practical tool, it provides little insight into what is arguably the most important aspect of the risk preference assessment problem. Specifically, despite the myriad analytical tools that have been developed, we are still left without an understanding of why individuals have different tolerances to risk, and how these attitudes may change over time. These are distinct, and deeper, questions than may be solved by simply assigning a client to a particular personality profile group. Given the inexorable link between risk-tolerance measures and the asset allocation decision, this distinction is important if we are to expand our level of precision any further. Therefore, rather than rely solely on observable demographic and psychometric variables, an attempt to find the underlying determinants of an investor's attitude toward risk-bearing would seem to warrant attention. 


\section{Experimental Measures of Risk Aversion}

\section{Investor Preferences and Experimental Markets ${ }^{1}$}

Two primary objectives of the remainder of this study are to examine explicit quantifications of risk aversion and to infer the relation between these statistics and other measurable characteristics of individuals. A possible byproduct of the effort to develop some underlying basis for the formation of economic preferences is that more formal and consistent approaches to assessing financial risk tolerance may also be established. Toward this end, it is appropriate to observe the behavior of individuals in actual market settings and, in so doing, infer their general attitudes toward bearing financial risk. Whereas there is an immense amount of data available on both securities prices and the portfolio holdings of individual and institutional investors, it is nevertheless difficult to determine the specific risk tolerance relations necessary for the purpose at hand. The reason for this is that real life is usually a poor laboratory. That is, it is difficult to control for variations in the myriad factors that intertwine to create an investor's economic and social fabric. Fortunately, alternative methodologies exist which allow us to simulate market conditions while obviating the influence of extraneous variables. Accordingly, this study makes use of recently developed theoretical and empirical tools to estimate risk-aversion parameters using experimental auction markets.

\footnotetext{
${ }^{1}$ This chapter develops the technical experimental procedures used to assess the risk-aversion parameters of individuals. After reading the first section of this chapter, readers interested primarily in the psychological and biochemical basis for risk aversion may skip to Chapter 3 without undue loss of continuity.
} 
As Smith (1982) has noted, the use of laboratory experiments in economics provides a manageable microeconomic environment where the control and measurement of relevant variables may be more precise than with the use of field data. In the present context, this control allows us to specify the explicit form of financial risk and, hence, estimate a measure of risk aversion. It also enables us to isolate potential age and gender effects, which were mentioned earlier as important cross-sectional characteristics delineating the nature of individual portfolio holdings. Thus, given the problems with drawing individual inferences from aggregate market data, experimental procedures are appropriate for the purposes at hand. More precisely, to obtain several independent measures of risk aversion, three separate "market institutions" are employed. These are: (1) the first price sealed bid auction, (2) the second price offer auction, and (3) the choices made among lottery pairs. The remainder of this chapter is devoted to providing the intuition and operational mechanics for each of these institutions. Chapter 3 describes the use of these three institutions in identifying factors underlying individuals' economic decision making.

\section{First Price Sealed Bid Auction}

The first price sealed bid auction provides a market environment in which an individual's attitudes toward assuming financial risk may be directly inferred. This type of auction corresponds to "... the usual practice of calling for the tender of bids on the understanding that the highest ... bid ... will be accepted and executed in accordance with its own term" (Vickrey 1961 and Cox, Roberson, and Smith 1982). Specifically, in an auction for a single unit of some commodity, each of $\mathbf{n}$ different bidders submits a bid in a sealed fashion (i.e., they are not made known to the other $(n-1)$ participants). The commodity is then awarded to the individual making the highest bid. If the intrinsic value of the commodity to the $\mathrm{j}^{\text {th }}$ participant is expressed as $\mathrm{v}_{\mathrm{j}}$, the income derived from winning the auction becomes $\left(v_{j}-b_{j}\right)$, where $b_{j}$ is the level of the submitted bid.

Assume every bidder has a utility function defined on income (y) of the form: ${ }^{2}$

${ }^{2}$ Rather than specifying utility as a function of total wealth as in Chapter 1, (5) is defined as changes in wealth. The normalization of utility on wealth is consistent with other theoretical analyses and experimental observations. 


$$
\mathrm{u}_{\mathrm{j}}\left(\mathrm{b}_{\mathrm{j}}\right)=(\mathrm{y})^{\mathrm{rj}}
$$

If each participant's objective will be to maximize the expected utility of his or her income, then this may be represented as:

$$
u_{j}\left(b_{j}\right)=\left(v_{j}-b_{j}\right)^{r_{j}}
$$

where $r_{j}$ denotes the constant relative risk aversion (CRRA) parameter estimated for the $\mathrm{j}^{\text {th }}$ individual using the experimental procedures documented in this study.

As shown in Appendix A, each individual will submit a bid according to the function:

$$
b_{j}=\left[\frac{n-1}{n-1+r_{j}}\right] \quad v_{j}
$$

given certain restrictions on the form of the auction and on the individual's expectations. Notice that a participant's bid in a given auction becomes a function of the value of the commodity (i.e., $v_{j}$ can be viewed as the value at which the commodity may be resold), the number of bidders in the auction, and the utility function exponent, $r$, which captures the bidder's attitude toward risk-bearing. In fact, this individual-specific parameter determines the degree of relative risk aversion. Recall from equation (4) that the relative risk aversion for the $j^{\text {th }}$ individual is expressed as:

$$
R R A_{j}=\frac{-w u_{j}^{\prime \prime}}{u_{j}^{\prime}}
$$

Using the assumed form of the bidder's utility function in (5), this may be written more simply as $R R A_{j}=\left(1-r_{j}\right)$. Thus, individuals are assumed to exhibit constant relative risk aversion (CRRA) of the order $\left(1-r_{j}\right)$. If $r_{j}$ is equal to 1.00 , then an investor is said to be risk neutral and, hence, indifferent to the amount of financial uncertainty in his or her portfolio. If $0<r_{j}<1$, on the other hand, the same individual would be regarded as risk averse.

To obtain a better understanding of the role of an investor's risk aversion within this market institution, consider Figure 5, which illustrates an actual 
series of bids in a set of first price auctions (specific operational details of the auction process are discussed below). In these auctions, the value of an abstract commodity that was the subject of the bidding process varied uniformly and randomly from $\$ 0.00$ to $\$ 10.00$. In each auction, the bid is typically less than the resale value (i.e., the bids fall below the 45 degree line). Clearly, the probability of a particular bidder winning a given auction is a function of the amount of the bid: the higher the bid, the greater the probability of winning the auction and receiving the unit of the commodity. What is also true, of course, is that as the bid increases to improve the chances of winning, the profits from winning (i.e., $v_{j}-b_{j}$ ) decrease. Thus, there is an explicit risk and return trade-off within this auction market. Risk-averse individuals are willing to bid a higher proportion of their resale values (i.e., decrease their profits from winning the auction) to increase their probability of winning.

\section{FIGURE 5}

\section{Example of a Series of First Price Auction Bids for Differing Resale Values}

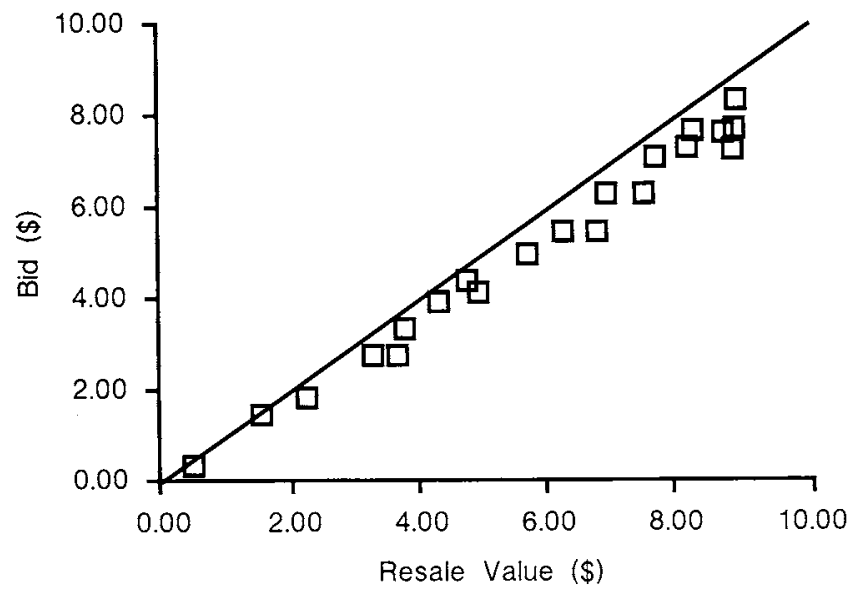

This simple risk-return trade-off represented by the bid decision provides the mechanism with which an individual's economic risk aversion may be estimated. Specifically, if individuals bid according to the linear function in (7) based upon a given set of conditions, then the proportion of their bids relative to resale values captures their propensity to bear risk. Over a series of $\mathrm{T}$ auctions, the regression: 


$$
b_{j t}=\alpha_{j}+\beta_{j} v_{j t}+\varepsilon_{j t} \quad t=1, \ldots, T
$$

provides estimates of $a_{j}$ and $\beta_{j}$, which describe the individual's bidding behavior across T auctions. As shown in Appendix A, an estimate of risk aversion is given by:

$$
\hat{r}_{j}=\frac{(n-1)\left(1-\hat{\beta_{j}}\right)}{\hat{\beta}_{j}} .
$$

For the series of auctions depicted in Figure 5, in which there were four participants (i.e., $n=4$ ), the estimate of $\beta_{j}$ from (9) is 0.8374 . Thus, $\hat{r}_{j}$ for this individual from (10) is 0.58 , which is consistent with risk-averse behavior.

\section{Second Price Offer Auction}

Another market institution which facilitates measurement of an individual's economic risk aversion is the second price offer auction. In this auction mechanism, participants tender offers to sell a property right instead of bidding to obtain this right (hence the term "offer auction"). It also differs in the manner in which the property right is priced in the auction. That is, the individual submitting the lowest offer would win the auction and sell their property right. They would receive an amount equal to the "second" lowest offer, however. This pricing mechanism ensures that auction participants submit offers that fully reflect the personal value assigned to the property right (i.e., their certainty equivalent). ${ }^{3}$

To see how this institution may be used to assess risk aversion, consider a property right in the form of a lottery ticket. This lottery may be expressed as $\mathrm{L}(\mathrm{w}, \mathrm{p} ; \mathrm{z})$, which describes a gamble offering a probability $\mathrm{p}$ of winning an amount $w$ and probability $(1-p)$ of losing an amount $z$. Recall from Chapter 1 that the certainty equivalent is the value placed on a risky prospect such that, given risk aversion, the individual is indifferent to receiving that value in exchange for the right to the prospect. If $b$ denotes an individual's revealed certainty equivalent (i.e., the tendered offer from the second price offer auction), then the expected utility for a lottery $L(w, p ; z)$ may be expressed as:

\footnotetext{
${ }^{3}$ This characteristic of the second price offer auction is referred to as full demand revelation, and it is known to be an optimal non-cooperative strategy.
} 


$$
u(b)=E[u(L)]=p u(w)+(1-p) u(z)
$$

If we once again assume that individual $j$ has a CRRA utility function of the form $\mathrm{u}(\mathrm{y})=(\mathrm{y})^{\mathrm{r}}$ in equation (5) and that $\mathrm{z}=0$, then (11) becomes: ${ }^{4}$

$$
(b)^{\mathrm{r} \dot{j}}=p(w)^{\mathrm{r} \dot{j}} \text {. }
$$

Taking the logarithm of both sides and rearranging terms yields:

$$
\ln (b)=\ln (w)+\frac{1}{r_{j}} \ln (p) .
$$

Over a series of $\mathrm{T}$ auctions in which the lottery payoff, $w$, is fixed and the probability of winning is varied over the range of 0 to 1.0 , the $1 / r_{j}$ term in (13) may be estimated from the regression:

$$
\ln \left(b_{j t}\right)=\gamma_{j}+\lambda_{j}\left(\ln \left(p_{t}\right)\right)+\varepsilon_{j t} \quad t=1, \ldots, T
$$

where the intercept term, $\gamma_{j}$, is constrained to a value equal to $\ln (w)$ and $\lambda_{j}$ is equal to the inverse of $r_{j}$. Thus, larger values of $\hat{\lambda}_{j}$ reflect more risk-averse behavior in the second price offer auction.

To illustrate this estimation procedure for the second price offer auction, consider the lottery $\mathrm{L}(5,000,0.68 ; 0)$ depicted in Figure 6 , in which payoffs are denoted in francs. ${ }^{5}$ For a random number chosen between 1 and 100 , this lottery ticket has an expected value of 3,400 francs. Assume that a risk-averse

\footnotetext{
${ }^{4}$ The use of a second price offer auction provides a more tractable representation of expected utility than that of a second price auction in which participants are bidding to purchase a property right. Specifically, equations (11) and (12) for this latter type of auction are:

$$
\begin{aligned}
\mathrm{u}(0) & =\mathrm{E}[\mathrm{u}(\mathrm{L}-\mathrm{b})]=\mathrm{p} \mathrm{u}(\mathrm{w}-\mathrm{b})+(1-\mathrm{p}) \mathrm{u}(\mathrm{z}-\mathrm{b}) \\
0 & =\mathrm{p}(\mathrm{w}-\mathrm{b})^{\mathrm{rj}}+(1-\mathrm{p})(-\mathrm{b})^{\mathrm{r}}
\end{aligned}
$$

Thus, inferences regarding $\mathrm{r}_{\mathrm{j}}$ are made more complicated by the presence of negative utility arguments. Offer auctions avoid this problem by confining the analysis to income gains resulting from the sale of the property right (i.e., the positive domain of the utility function).

${ }^{5}$ Francs are used as the numeraire for experimental purposes with a conversion ratio to dollars (i.e., 2,000 francs equal $\$ 1.00$ ).
} 
individual currently owns this ticket and submits an offer to sell it for 3,180 francs. This offer represents the individual's certainty equivalent for the gamble and from (13),

$$
\ln (3,180)=\ln (5,000)+\frac{1}{r_{j}} \ln (0.68) .
$$

Solving for $\mathrm{r}_{\mathrm{j}}$, we find that the estimate of the individual's risk aversion taken from this single observation is 0.85 . For a sequence of auctions, a more general statistical approach to this estimation is obtained from the regression equation in (14).

\section{FIGURE 6}

\section{Example of Lottery Ticket in a Second Price Offer Auction}

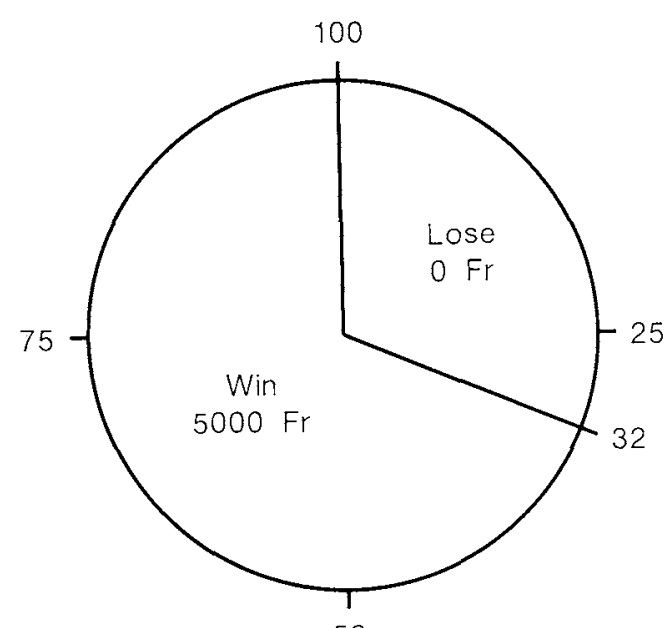

\section{Lottery Pair Choices}

50

A third approach to inferring risk aversion may be found in the indicated preferences among a set of risky prospects. Specifically, consider the lottery pair presented in Figure 7. Bet $A$ in this figure may be characterized as a probability bet (P-bet) in which there is a large probability of winning a certain amount of money (4,000 francs). Bet $B$, on the other hand, represents a dollar bet ( $D$-bet) because there is only a small probability $(\mathrm{p}=0.19)$ of winning a larger amount of money $(18,000$ francs). 


\section{FIGURE 7}

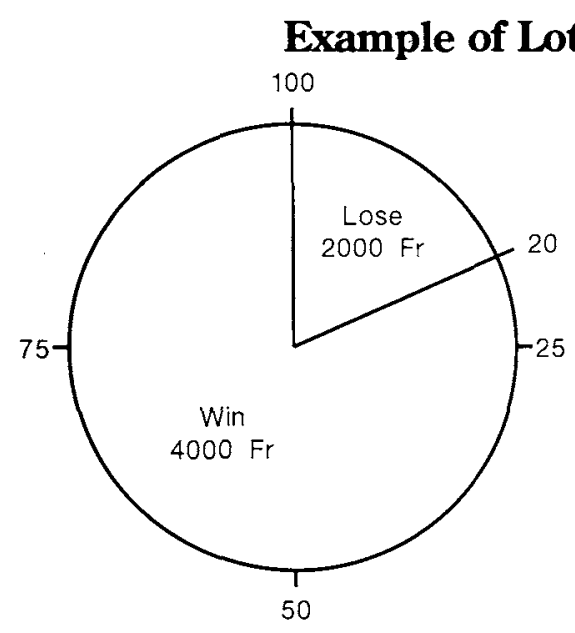

Bet $A$

(Probability Bet)

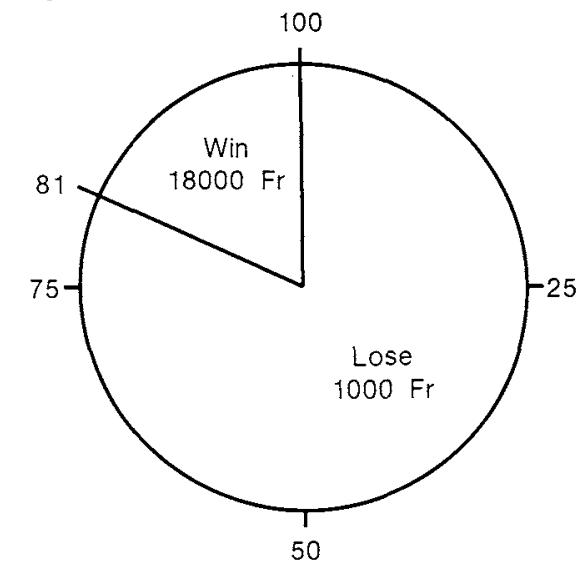

Bet $B$

(Dollar Bet)

To remain consistent with the discussion in the previous chapter, assume an individual exhibits CRRA with a power utility function of the form in (5) and with exponent $r_{j}$. An individual, in determining which of two gambles is preferred, may be viewed as comparing the expected utility offered from each. Bet $A$ will be preferred to bet $B$ if $E\left[u\left(L_{A}\right)\right]>E\left[u\left(L_{B}\right)\right]$, where $L_{A}$ and $L_{B}$ denote the lottery payoffs of the form L $(w, p ; z)$ for $A$ and $B$, respectively. Substituting for the lottery and utility function, A will be preferred to $B$ if:

$$
p_{A}\left(w_{A}\right)^{r j}-\left(1-p_{A}\right)\left(\left|z_{A}\right|\right)^{r j}>p_{B}\left(w_{B}\right)^{r j}-\left(1-p_{B}\right)\left(\left|z_{B}\right|\right)^{r j}
$$

where absolute values for $z$ are employed to provide a real solution for negative utility arguments. ${ }^{6}$

Alternatively, this comparison could be recast as one in which the individual's utility function is compared with that of a hypothetical individual who is indifferent between the two gambles and who has a utility exponent

${ }^{6}$ This assumption implies a utility function for $r_{j}<1\left(r_{j}>1\right)$ that is strictly concave (convex) for gains and strictly convex (concave) for losses and is thus consistent with experimentally observed behavior (see Kahneman and Tversky 1979). 
defined as $r_{p}$. That is, an individual with a utility exponent, $r_{j}$, should prefer the P-bet lottery (i.e., bet A) if $r_{p}>r_{j}$, and the D-bet lottery (i.e., bet $B$ ) if $r_{p}<r_{j}$. Thus, larger values of $r_{p}$ reflect an increase in risk of the $D$-bet relative to the P-bet for an individual exhibiting CRRA. ${ }^{7}$

Based on this relationship, the pattern of choices between a series of P-bets and D-bets may be used in conjunction with lottery pair $r_{p}$ values to obtain a measure of risk aversion. To see this, assume that a set of lottery pairs similar to that in Figure 7 were ordered from low $r_{p}$ values to high. For normal risk-averse behavior, one would expect to see an individual indicating a preference for P-bets for $r_{p}>r_{j}$ and for D-bets for $r_{p}<r_{j}$. Because the individual is making a simple binary choice, logistic regression is particularly useful in analyzing this decision and inferring the $r_{p}$ value at which the individual would be indifferent between the two bets. That is, the probability of making a P-bet (or D-bet) may be estimated based on actual choices for each $r_{p}$ value, and the $r_{p}$ value determined for which the probability of making a P-bet is 0.5 . Additional details of this procedure are discussed in Chapter 3.

${ }^{7}$ The value of $r_{p}$ is unique and is determined numerically such that it satisfies:

$p_{A}\left(w_{A}\right)^{r p}-\left(1-p_{A}\right)\left(\left|z_{A}\right|\right)^{r p}=p_{B}\left(w_{B}\right)^{r p}-\left(1-p_{B}\right)\left(\left|z_{B}\right|\right)^{r p}$. 


\section{A New Perspective of Risk Aversion}

As discussed in Chapter 1, our present understanding of investor risk aversion and its determinants may best be described as qualitative in nature. Because of the complex nature of observable human behavior, we have only been able to assess broad characteristics that seem to delineate classes of investors. The motivation of this study is to proceed in a direction of quantifying individual economic preferences and at the same time providing a tangible link to what we currently know about this form of behavior. More specifically, a primary objective of this study is to examine individual-specific characteristics that may play an important role in establishing risk aversion. Toward this end, we now turn to a relatively new area of research that has established a relation between biological factors and certain personality traits. Specific aspects of these investigations are suggestive of additional parallel relations to economic behavior.

\section{The Biochemical and Psychological Basis for Risk Aversion}

As detailed in Harlow (1988), recent research in the area of behavioral biology has provided new insights into the interaction of neurochemical processes and human behavior. In particular, the entire neurotransmission process, generally described as catecholamine systems activity, appears to be closely associated with specific personality characteristics of individuals (see Zuckerman 1984 for a review of an extensive literature). That is, behavioral traits termed sensation seeking, impulsivity, and extroversion have been found to be related to this biochemical activity.

To aid in understanding the neurochemical systems that have been the focus of this research, Figure 8 presents a stylized representation of important aspects of the processes governing the three biogenic amine neurotransmit- 
ters: dopamine, serotonin, and norepinephrine. Specifically, the production, rate of release, metabolism, disposal, and receptor sensitivity of these biochemicals are related to observable behavior. Two neuroregulating enzymes involved in these processes are dopamine-beta-hydroxylase (DBH) and monoamine oxidase (MAO). DBH is an enzyme that converts dopamine to norepinephrine, whereas MAO degrades all three of the neurotransmitters. Zuckerman, Ballenger, Jimerson, Murphy, and Post (1983) have established that individuals with high sensation-seeking tendencies, impulsivity, and extroversion have been shown to have, on average, lower levels of DBH and MAO (as measured within serum/plasma and blood platelets, respectively). ${ }^{1}$

\section{FIGURE 8}

\section{Monamine Neurotransmitters, Enzymes, and Metabolites}

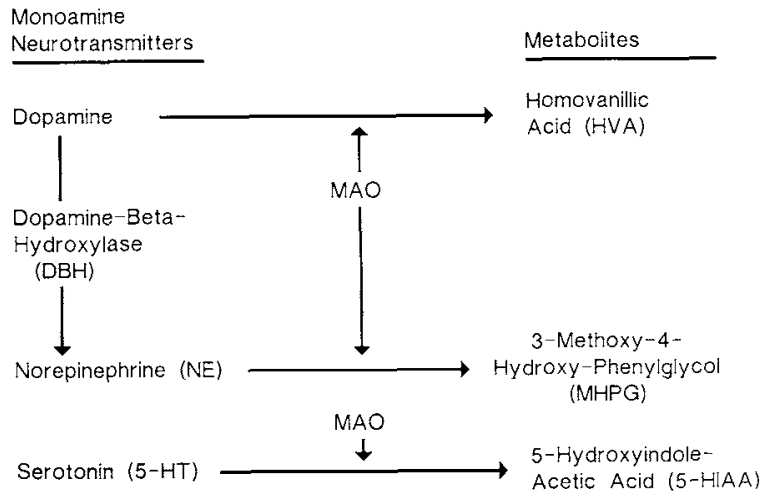

Source: Adapted from Zuckerman (1983) and used with permission from the publisher, Lawrence Erlbaum Associates, Hillsdale, New Jersey.

The individual behavioral traits described by sensation seeking and impulsivity parallel the notion of economic risk aversion, thereby suggesting the possibility of biological influences on economic preferences. For example, psychometric-measured sensation seeking traits reflect an individual's propen-

\footnotetext{
${ }^{1}$ Sensation-seeking traits and the levels of platelet MAO have both been found to have a high genetic influence. Fulker, Eysenck, and Zuckerman (1980) found a substantial heritability of 58 percent ( 69 percent when corrected for reliability) for sensation-seeking traits using biometric methods. Nies, Robinson, Lamborn, and Lambert (1973) found an 80 percent heritability for platelet MAO levels.
} 
sity to engage in such risky activities as sports and some aspects of risk taking within those activities (Zuckerman, Buchsbaum, and Murphy 1980). Studies involving anticipated risk indicate that low sensation seekers showed high risk appraisals of a variety of situations and anticipation of greater fear and less pleasure if actually exposed to those situations (Zuckerman 1979a). In addition, these traits relate to cognitive, perceptual, and aesthetic preferences as well as vocational interests and choices (Zuckerman 1979b).

Measures of sensation seeking, impulsivity, and extroversion can be obtained from psychological tests. The primary psychometric measure is derived from Form V of the sensation-seeking scale (SSS) (Zuckerman, Eysenck, and Eysenck 1978 and Zuckerman 1979b). The SSS has a general sensation seeking scale (Gen) as well as four subscales: thrill and adventure seeking (TAS), experience seeking (ES), disinhibition (Dis), and boredom susceptibility (BS). ${ }^{2}$ Sensation seeking has been found to be negatively correlated with platelet MAO (Murphy, Belmaker, Buchsbaum, Martin, Ciaranello, and Wyatt 1977 and Schooler, Zahn, Murphy, and Buchsbaum 1978) and with other measures of catecholamine activity (Zuckerman, et al. 1983). ${ }^{3}$

Additional evidence suggesting an interrelation between biochemical processes and economic risk aversion is based on characteristics of sensation seeking traits and platelet MAO and plasma DBH levels. In particular, males score significantly higher than females on all of the various sensation seeking psychometric scales (Zuckerman, et. al. 1978), and males have been found to have lower levels of platelet MAO at nearly all ages between 18 and 75 (Robinson, Davis, Nies, Ravaris, and Sylvester 1971, and Murphy, Wright, Buchsbaum, Nichols, Costa, and Wyatt 1976). Further, sensation seeking has been found to be negatively related to age (Zuckerman, et. al. 1980) and platelet MAO levels positively related to age (Robinson, et. al. 1971). All of these findings are consistent with empirically observed characteristics of

\footnotetext{
${ }^{2}$ Each of the four subscales represents responses to 10 question items and is scored based on the number of relevant responses ( 0 to 10$)$. The Gen scale is the sum of the four subscales and, thus, ranges in value from 0 to 40 .

${ }^{3}$ Sensation seeking has also been found to be related to a neurological function involving cortical evoked potentials (Buchsbaum 1971, Zuckerman, Murtaugh, and Siegel 1974, and others). Specifically, the brain response to various external stimuli can be measured through the evoked potential with an electroencephalogram (EEG). These responses have been found to be reliable psychophysiological trait measures.
} 
individuals' perception of risk and the riskiness of their portfolio holdings, as discussed in Chapter 1. Thus, the traditional view of a life-cycle pattern of risk aversion (i.e., increasing risk aversion with age) is consistent with both observed investment behavior and the intertemporal properties of the aforementioned psychological and biochemical traits. ${ }^{4}$

Based on this evidence, the primary hypothesis investigated by this study is that neurochemical processes play a role, all other things being equal, in determining an individual's economic preferences. Individuals with catecholamine activity characterized by lower levels of DBH and MAO (i.e., high sensation-seeking, impulsive, and extroverted individuals) are hypothesized to be economically less risk averse than individuals with higher levels of DBH and MAO (i.e., low sensation-seeking, non-impulsive, and introverted individuals). The next section describes the experimental procedures used in exploring this hypothesis.

\section{Experimental Procedures}

The data for the economic, biochemical, and psychometric measures discussed in the preceding sections were developed from a series of experimental sessions using a total of 183 student subjects at the University of Arizona. In the first session, subjects in groups of four to eight participated in two sequences of 25 first price sealed bid auctions each using the PLATO/NovaNet computer system. ${ }^{5}$ The experiments were designed to follow the same general procedures utilized by Cox, Smith, and Walker (1984, 1985b, 1987) and Walker, Smith, and Cox (1987). In the first sequence, subjects competed against 3 (5) competitors; in the second, against 5 (3) competitors. That is, an $\mathrm{AB} / \mathrm{BA}$ experimental design was employed in which one half of the subjects participated in an $n=4$ and $n=6$ auction sequence and the other half in $\mathrm{n}=6$ and $n=4$ sequence.

\footnotetext{
${ }^{4} \mathrm{~A}$ biological basis for risk aversion is also indirectly suggested from the economic research using animal subjects. As Battalio, Kagel, and MacDonald (1985) have documented, the choices among gambles for laboratory animals are consistent with risk-averse behavior. Such behavior suggests that economic preferences are not uniquely human and not totally dependent on human learning, experience, and social structures. Thus, it can be inferred that there is some common biological thread.

${ }^{5}$ PLATO/NovaNet is a time-slicing educational mainframe computer system developed at the Center for Educational-based Research Laboratory (CERL) at the University of Illinois. The system has been used extensively for instructional research in experimental economics.
} 
Student subjects were volunteer recruits from undergraduate economics courses. Each subject was paid $\$ 3.00$ upon arrival and informed that he or she would be participating in a series of experiments involving economic decision making. The subjects completed a short questionnaire providing basic demographic information as well as their prior experience in other PLATO/NovaNet experiments and auctions. Subjects then reviewed a computerized set of instructions detailing the nature and procedures of the first price auction (the entire set of these instructions is reported by Cox, Smith, and Walker 1985a). These instructions explained in nontechnical language that the "resale values" for an abstract commodity being auctioned were drawn independently and randomly from a set of integers (i.e., cents) contained in an interval $(0, \vec{v})$. Subjects were informed that they would be bidding against 3 (5) computerized competitors with $\overline{\mathrm{v}}=\$ 10.00$ ( $\$ 21.00)$ (see Walker, et. al. 1987 for an example of the instructions informing subjects of the use of Nash computerized competitors). ${ }^{6}$ They were not informed of the total number of auctions in which they would be participating.

Following the first series of auctions, the PLATO/NovaNet system was reinitialized and subjects were informed that they would be competing against 5 (3) computerized competitors with a new $\bar{v}=\$ 21.00$ ( $\$ 10.00)$. After completion of this sequence, subjects were offered an additional $\$ 3.00$ to complete the 40-question SSS Form V. This session lasted approximately 1.5 hours.

In the second experimental session, subjects were recruited from the total pool of first price auction participants and asked to complete the Minnesota Multiphasic Personality Inventory (MMPI) (Hathaway and McKinley 1951) in exchange for $\$ 10.00$ (in addition to $\$ 3.00$ paid upon arrival). This test was employed as an additional psychometric measure of the relevant personality characteristics. Of the various traits measured by this test, the $\mathrm{Si}$ (social introversion) scale has been found by Zuckerman, et al. (1983) to be significantly correlated with measures of catecholamine activity. This scale is used as an independent measure of extroversion. ${ }^{7}$ A total of 102 subjects from the first session group (183 subjects) completed this phase of the research. This session lasted approximately 1.5 hours.

\footnotetext{
${ }^{6}$ The $\bar{v}$ of $\$ 10.00$ for the $n=4$ auctions and $\$ 21.00$ for the $n=6$ auctions provide the same expected payoffs for a risk-neutral bidder. See Appendix A for additional details regarding $\bar{v}$.

${ }^{7}$ Raw scores for the Si scale were used and potentially range from 0 to 70 based on the relevant responses to certain question items.
} 
For the third session, a total of 100 subjects from the previous sessions participated in the lottery pair choice experiment and second price auctions. In groups of approximately 10 subjects, instructions were provided explaining the nature of the experiment and the graphical depiction of lottery gambles (see Appendix B). Accompanying these instructions were the 16 lottery pair figures (listed in Table 1 and of the form presented earlier in Figure 7), and subjects were asked to indicate their preferences (or indifference) on an answer sheet. Subjects were reminded that one of the lottery pairs would be selected at random and played at the end of the experimental session. Following these choices, subjects were provided with instructions similar to those of Harless (1987) detailing the second price and second price offer auctions (see Appendix C). These instructions informed the subjects of the optimal bidding strategy for this institution. A notebook containing lottery figures was provided, and two example auctions were then played to ensure that subjects understood the nature of the experiment. A total of 26 auctions for the lottery tickets were then completed. Table 2 details the subset of nine of the lottery tickets that were used to estimate participants' risk aversion. ${ }^{8}$ Auctions were run in an open classroom with all bids and offers submitted in a sealed fashion. Winnings and losses were posted to individual balances following the outcome of each auction. Finally, a lottery pair was chosen at random and played. The outcome was determined for each individual depending on their prior choice, and earnings were adjusted accordingly.

The final experimental session consisted of obtaining a measure of catecholamine activity. As discussed earlier, two neuroregulating enzymes, $\mathrm{DBH}$ and MAO, play an important role in the set of neurochemical processes. In particular, $\mathrm{DBH}$ is involved in the conversion of the amine neurotransmitter dopamine to norepinephrine; $\mathrm{MAO}$ is involved in the degradation of dopamine, norepinephrine, and serotonin into various metabolites. Because these neurochemical processes take place within the brain, derivative measures of this activity must be employed for human subjects. Figure 9 provides a summary of several of these derivative measures. Zuckerman, et al. (1983) have investigated a wide range of alternative measures of this activity. Plasma

${ }^{8}$ The other 17 lottery tickets (not reported in Table 2) were a combination of second price and second price offer auctions used to investigate other hypotheses regarding economic preferences. These hypotheses as well as the associated experimental details are reported in Harlow (1988). 


\section{TABLE 1}

\section{Lottery Pairs for the Risk-Aversion Experiment}

\begin{tabular}{|c|c|c|c|c|c|c|}
\hline Pair & $\begin{array}{c}\text { Type } e^{\mathrm{a}} \\
\text { (1) }\end{array}$ & $\begin{array}{l}\text { Probability } \\
\text { of Win } \\
\text { (2) }\end{array}$ & $\begin{array}{l}\text { Amount } \\
\text { if Win } \\
\text { (3) }\end{array}$ & $\begin{array}{l}\text { Amount } \\
\text { if Lose } \\
\text { (4) }\end{array}$ & $\begin{array}{c}\text { Expected } \\
\text { Value } \\
\text { (5) }\end{array}$ & $\begin{array}{c}\text { Risk } \\
\text { Measure }\left(r_{p}\right)^{\mathrm{c}} \\
(6)\end{array}$ \\
\hline 1 & $\begin{array}{l}\mathrm{P} \\
\mathrm{D}\end{array}$ & $\begin{array}{l}0.68 \\
0.34\end{array}$ & $\begin{array}{l}3.00 \\
7.00\end{array}$ & $\begin{array}{l}-2.50 \\
-1.50\end{array}$ & $\begin{array}{l}1.24 \\
1.39\end{array}$ & 0.94 \\
\hline 2 & $\begin{array}{l}\mathrm{P} \\
\mathrm{D}\end{array}$ & $\begin{array}{l}0.86 \\
0.31\end{array}$ & $\begin{array}{l}2.50 \\
6.50\end{array}$ & $\begin{array}{l}-2.00 \\
-1.00\end{array}$ & $\begin{array}{l}1.87 \\
1.33\end{array}$ & 1.21 \\
\hline 3 & $\begin{array}{l}\mathrm{P} \\
\mathrm{D}\end{array}$ & $\begin{array}{l}0.80 \\
0.19\end{array}$ & $\begin{array}{l}2.00 \\
9.00\end{array}$ & $\begin{array}{l}-1.00 \\
-0.50\end{array}$ & $\begin{array}{l}1.40 \\
1.31\end{array}$ & 1.04 \\
\hline 4 & $\begin{array}{l}\mathrm{P} \\
\mathrm{D}\end{array}$ & $\begin{array}{l}0.83 \\
0.50\end{array}$ & $\begin{array}{l}3.00 \\
6.50\end{array}$ & $\begin{array}{l}-3.00 \\
-1.00\end{array}$ & $\begin{array}{l}1.98 \\
2.75\end{array}$ & 0.74 \\
\hline 5 & $\begin{array}{l}\mathrm{P} \\
\mathrm{D}\end{array}$ & $\begin{array}{l}0.94 \\
0.36\end{array}$ & $\begin{array}{l}1.50 \\
4.50\end{array}$ & $\begin{array}{l}-2.50 \\
-1.00\end{array}$ & $\begin{array}{l}1.26 \\
0.98\end{array}$ & 1.12 \\
\hline 6 & $\begin{array}{l}\mathrm{P} \\
\mathrm{D}\end{array}$ & $\begin{array}{l}0.80 \\
0.20\end{array}$ & $\begin{array}{l}0.00 \\
0.00\end{array}$ & $\begin{array}{l}-6.00 \\
-1.50\end{array}$ & $\begin{array}{l}-1.20 \\
-1.20\end{array}$ & 1.00 \\
\hline 7 & $\begin{array}{l}\mathrm{P} \\
\mathrm{D}\end{array}$ & $\begin{array}{l}0.73 \\
0.40\end{array}$ & $\begin{array}{l}2.50 \\
6.00\end{array}$ & $\begin{array}{l}-2.00 \\
-1.50\end{array}$ & $\begin{array}{l}1.29 \\
1.50\end{array}$ & 0.91 \\
\hline 8 & $\begin{array}{l}\mathrm{P} \\
\mathrm{D}\end{array}$ & $\begin{array}{l}0.90 \\
0.25\end{array}$ & $\begin{array}{l}2.50 \\
7.00\end{array}$ & $\begin{array}{l}-1.00 \\
-1.50\end{array}$ & $\begin{array}{l}2.15 \\
0.63\end{array}$ & 1.54 \\
\hline 9 & $\begin{array}{l}\mathrm{P} \\
\mathrm{D}\end{array}$ & $\begin{array}{l}0.72 \\
0.38\end{array}$ & $\begin{array}{l}3.00 \\
5.50\end{array}$ & $\begin{array}{l}-2.50 \\
-0.50\end{array}$ & $\begin{array}{l}1.46 \\
1.78\end{array}$ & 0.82 \\
\hline 10 & $\begin{array}{l}\mathrm{P} \\
\mathrm{D}\end{array}$ & $\begin{array}{l}0.92 \\
0.50\end{array}$ & $\begin{array}{l}2.00 \\
5.00\end{array}$ & $\begin{array}{l}-2.00 \\
-1.50\end{array}$ & $\begin{array}{l}1.68 \\
1.75\end{array}$ & 0.98 \\
\hline
\end{tabular}

${ }^{\text {ap }}$ denotes a probability bet; D, a dollar bet (see Figure 7).

${ }^{b}$ Amounts are reported in dollars while the actual lottery pairs presented to experimental subjects were converted to francs ( $\$ 1.00$ equal to 2,000 fr.).

${ }^{c}$ The $r_{p}$ values characterize the relative riskiness of the two bets within each lottery pair. A CRRA expected utility maximizer with a utility function exponent equal to $r_{p}$ would be indifferent between the two lotteries (where $\left(1-r_{p}\right)$ is the Arrow-Pratt CRRA parameter).

Continued on next page. 


\section{TABLE 1 (Continued)}

\begin{tabular}{|c|c|c|c|c|c|c|}
\hline Pair & $\begin{array}{c}\text { Type } e^{\mathrm{a}} \\
\text { (1) }\end{array}$ & $\begin{array}{l}\text { Probability } \\
\text { of Win } \\
\text { (2) }\end{array}$ & $\begin{array}{l}\text { Amount } \\
\text { if Win b } \\
\text { (3) }\end{array}$ & $\begin{array}{l}\text { Amount } \\
\text { if Lose } \\
\text { (4) }\end{array}$ & $\begin{array}{c}\text { Expected } \\
\text { Value } \\
\text { (5) }\end{array}$ & $\begin{array}{c}\text { Risk } \\
\text { Measure }\left(r_{p}\right) \\
(6)\end{array}$ \\
\hline 11 & $\begin{array}{l}\mathrm{P} \\
\mathrm{D}\end{array}$ & $\begin{array}{l}0.83 \\
0.33\end{array}$ & $\begin{array}{l}2.50 \\
6.50\end{array}$ & $\begin{array}{l}-1.00 \\
-1.50\end{array}$ & $\begin{array}{l}1.91 \\
1.14\end{array}$ & 1.28 \\
\hline 12 & $\begin{array}{l}\mathrm{P} \\
\mathrm{D}\end{array}$ & $\begin{array}{l}0.80 \\
0.35\end{array}$ & $\begin{array}{l}2.50 \\
7.00\end{array}$ & $\begin{array}{l}-2.00 \\
-0.50\end{array}$ & $\begin{array}{l}1.60 \\
2.13\end{array}$ & 0.81 \\
\hline 13 & $\begin{array}{l}\mathrm{P} \\
\mathrm{D}\end{array}$ & $\begin{array}{l}0.88 \\
0.27\end{array}$ & $\begin{array}{l}2.00 \\
5.00\end{array}$ & $\begin{array}{l}-2.50 \\
-0.50\end{array}$ & $\begin{array}{l}1.46 \\
0.99\end{array}$ & 1.25 \\
\hline 14 & $\begin{array}{l}\mathrm{P} \\
\mathrm{D}\end{array}$ & $\begin{array}{l}0.90 \\
0.18\end{array}$ & $\begin{array}{r}2.00 \\
10.00\end{array}$ & $\begin{array}{l}0.00 \\
0.00\end{array}$ & $\begin{array}{l}1.80 \\
1.80\end{array}$ & 1.00 \\
\hline 15 & $\begin{array}{l}\mathrm{P} \\
\mathrm{D}\end{array}$ & $\begin{array}{l}0.75 \\
0.42\end{array}$ & $\begin{array}{l}3.00 \\
6.00\end{array}$ & $\begin{array}{l}-2.50 \\
-1.00\end{array}$ & $\begin{array}{l}1.63 \\
1.94\end{array}$ & 0.86 \\
\hline 16 & $\begin{array}{l}\mathrm{P} \\
\mathrm{D}\end{array}$ & $\begin{array}{l}0.82 \\
0.33\end{array}$ & $\begin{array}{l}2.50 \\
6.50\end{array}$ & $\begin{array}{l}-2.50 \\
-1.00\end{array}$ & $\begin{array}{l}1.60 \\
1.48\end{array}$ & 1.05 \\
\hline
\end{tabular}

$\mathrm{DBH}$ and platelet $\mathrm{MAO}$ have been found to be correlated with these alternative measures and with psychometric measures of sensation seeking, impulsivity, and extroversion. Based on this research, plasma DBH tends to be a better biochemical measure than platelet MAO and more highly correlated with the relevant psychometric measures. At the time of this study, however, clinical laboratories were not available to conduct a DBH assay. Consequently, a platelet MAO measure was used notwithstanding that the clinical procedures involved with this test are more difficult. ${ }^{9}$ Accordingly, volunteers were solicited to give a small blood sample (approximately $20 \mathrm{ml}$.) to determine platelet levels of MAO. A total of 125 subjects volunteered and were paid $\$ 15.00$ for participation. Of this number, 67 were male and 58 were female, and the majority had completed all three of the prior experimental sessions.

${ }^{9}$ Platelet MAO levels are stable clinical traits with retest reliabilities (correlations) of 0.94 (1-2 week interval) and 0.86 (8-10 week interval) (Murphy, Wright, Buchsbaum, Nichols, Costa, and Wyatt 1976). For this study, MAO was measured using a C14 tryptamine enzyme substrate with units in nanomoles $/ \mathrm{hr} / \mathrm{miligram}$ of platelet protein. 


\section{TABLE 2}

\section{Second Price Offer Auctions}

$\begin{array}{ccccc}\text { Auction }^{\mathrm{a}} & \begin{array}{c}\text { Probability } \\ \text { of Win } \\ (1)\end{array} & \begin{array}{c}\text { Amount } \\ \text { if Win } \\ (2)\end{array} & \begin{array}{c}\text { Amount } \\ \text { if Lose } \\ (3)\end{array} & \begin{array}{c}\text { Expected } \\ \text { Value } \\ (4)\end{array} \\ 1 & 0.56 & 5.00 & 0.00 & 2.80 \\ 4 & 0.16 & 5.00 & 0.00 & 0.80 \\ 8 & 0.68 & 5.00 & 0.00 & 3.40 \\ 11 & 0.44 & 5.00 & 0.00 & 2.20 \\ 15 & 0.80 & 5.00 & 0.00 & 4.00 \\ 18 & 0.04 & 5.00 & 0.00 & 0.20 \\ 21 & 0.24 & 5.00 & 0.00 & 1.20 \\ 23 & 0.92 & 5.00 & 0.00 & 4.60 \\ 26 & 0.35 & 5.00 & 0.00 & 1.75\end{array}$

${ }^{a}$ The nine auctions listed are a subset of 26 auctions implemented as a part of other preference experiments. See Harlow (1988) for additional details.

\footnotetext{
${ }^{\mathrm{b}}$ Amounts are reported in dollars while the actual auction lottery pairs presented to experimental subjects were converted to francs ( $\$ 1.00$ equal to $2,000 \mathrm{fr}$.).
}

\section{Experimental Results: Individuals}

Based on the experimental design in the previous discussions, three general measures of economic preferences have been developed. These independent measures of relative risk aversion were derived from: (1) first price auctions and a Nash equilibrium bidding model (equations (9) and (10)); (2) second price offer auctions and parameter estimates of a utility function (equation (14)); and (3) the pattern of choices among a set of lottery pairs. The relationship of these measures to biochemical and related psychometric measures are discussed in subsequent sections.

As a starting point for the analysis, male and female experimental subjects were rank-ordered separately using: (1) the platelet level of the neuroregulat- 
ing enzyme MAO; (2) the general (Gen) sensation seeking score from Form $\mathrm{V}$ of the SSS; and (3) the social introversion (Si) score from the MMPI. Two approximately equal-sized groups within each gender were then identified, one on either side of the median values for each of these variables. This simple dichotomization procedure to define biological subgroups was used throughout all statistical analyses to maintain methodological consistency across different market institutions and experiments. It was also used to avoid the specification of a parametric relation between the various measures.

Table 3 provides a summary of the mean values for these three biochemical-psychometric variables and for subject age (using MAO as the rank variable) within these rank-ordered subgroups. In addition, the table compares these variables for males, females, and the total experimental subject group. Inspection of this table reveals that the subject sample was homogeneous with respect to age, and that males and females differ across the biochemical-psychometric variables in a manner consistent with earlier research.

Differences between the risk-aversion parameters developed from the first price and second price offer auctions were then compared across these groups

\section{FIGURE 9}

Biochemical Measures of Catecholamine Systems Activity

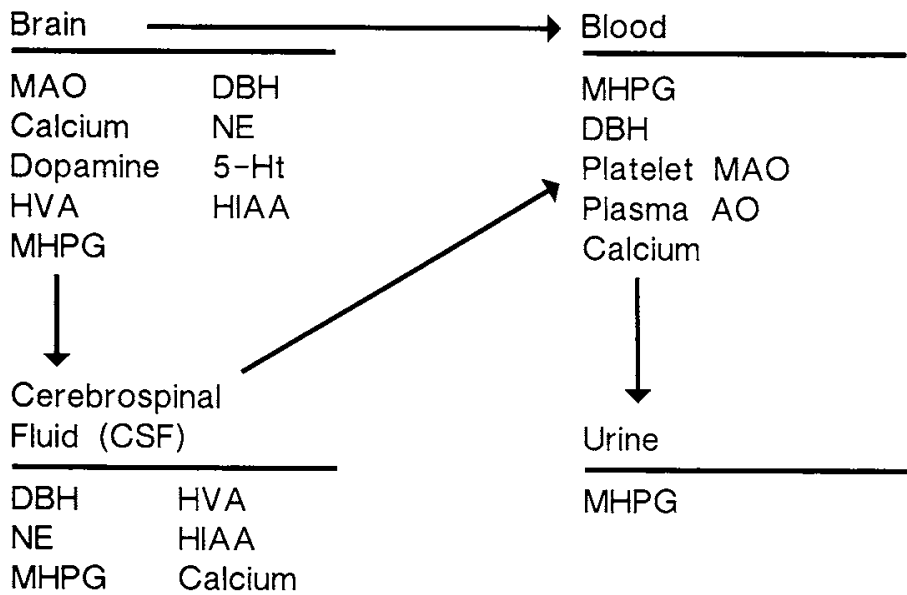

Source: Adapted from Zuckerman (1983) and used with permission from the publisher, Lawrence Erlbaum Associates, Hillsdale, New Jersey. 


\section{TABLE 3}

\section{Summary Statistics for Experimental Subject Groups}

\begin{tabular}{|c|c|c|c|c|c|c|c|}
\hline \multirow[b]{2}{*}{$\begin{array}{c}\text { Variable }^{\mathrm{a}} \\
\underset{X}{(1)}\end{array}$} & \multirow[b]{2}{*}{$\begin{array}{c}\text { All } \\
\text { Subjects } \\
\text { (2) }\end{array}$} & \multirow[b]{2}{*}{$\begin{array}{c}\text { Males } \\
\text { (3) }\end{array}$} & \multirow[b]{2}{*}{$\begin{array}{c}\text { Females } \\
\text { (4) }\end{array}$} & \multicolumn{2}{|c|}{ Males } & \multicolumn{2}{|c|}{ Females } \\
\hline & & & & $\begin{array}{c}\text { Low } \\
\text { Rank } X \\
\text { (5) }\end{array}$ & $\begin{array}{c}\text { High } \\
\text { Rank X } \\
\text { (6) }\end{array}$ & $\begin{array}{c}\text { Low } \\
\text { Rank X } \\
\text { (7) }\end{array}$ & $\begin{array}{l}\text { High } \\
\text { RankX } \\
\quad(8)\end{array}$ \\
\hline $\begin{array}{l}\text { MAO } \\
\text { (SE) } \\
\text { n }\end{array}$ & $\begin{array}{c}5.18 \\
(0.16) \\
125\end{array}$ & $\begin{array}{l}4.27 \\
(0.15) \\
67\end{array}$ & $\begin{array}{c}6.22 \\
(0.22) \\
58\end{array}$ & $\begin{array}{l}3.25 \\
(0.13) \\
33\end{array}$ & $\begin{array}{l}5.26 \\
(0.13) \\
34\end{array}$ & $\begin{array}{l}4.94 \\
(0.14) \\
29\end{array}$ & $\begin{array}{l}7.51 \\
(0.23) \\
29\end{array}$ \\
\hline $\begin{array}{l}\text { Gen } \\
\text { (SE) } \\
\mathrm{n}\end{array}$ & $\begin{array}{c}20.59 \\
(0.44) \\
170\end{array}$ & $\begin{array}{l}21.86 \\
(0.58) \\
92\end{array}$ & $\begin{array}{l}19.09 \\
(0.63) \\
78\end{array}$ & $\begin{array}{l}17.35 \\
(0.52) \\
46\end{array}$ & $\begin{array}{l}26.37 \\
(0.44) \\
46\end{array}$ & $\begin{array}{l}14.39 \\
(0.56) \\
36\end{array}$ & $\begin{array}{l}23.12 \\
(0.53) \\
42\end{array}$ \\
\hline $\begin{array}{l}\mathrm{Si} \\
(\mathrm{SE}) \\
\mathrm{n}\end{array}$ & $\begin{array}{c}24.19 \\
(0.77) \\
139\end{array}$ & $\begin{array}{l}23.83 \\
(0.99) \\
76\end{array}$ & $\begin{array}{l}24.63 \\
(1.20) \\
63\end{array}$ & $\begin{array}{l}17.13 \\
(0.49) \\
38\end{array}$ & $\begin{array}{l}30.53 \\
(1.15) \\
38\end{array}$ & $\begin{array}{l}16.84 \\
(0.79) \\
31\end{array}$ & $\begin{array}{l}32.19 \\
(1.15) \\
32\end{array}$ \\
\hline $\begin{array}{l}\text { Age } \\
\text { (SE) } \\
\mathrm{n}\end{array}$ & $\begin{array}{c}21.60 \\
(0.27) \\
183\end{array}$ & $\begin{array}{l}22.00 \\
(0.39) \\
98\end{array}$ & $\begin{array}{l}21.15 \\
(0.37) \\
85\end{array}$ & $\begin{array}{l}21.56 \\
(0.57) \\
33\end{array}$ & $\begin{array}{l}21.73 \\
(0.49) \\
34\end{array}$ & $\begin{array}{l}21.52 \\
(0.77) \\
29\end{array}$ & $\begin{array}{l}20.74 \\
(0.64) \\
29\end{array}$ \\
\hline
\end{tabular}

${ }^{2}$ Standard errors (SE) and the number of observations (n) are listed below the means of each group. MAO is reported in nanomoles/hr/milligram of platelet protein (C14 tryptamine enzyme substrate). Gen and $\mathrm{Si}$ scores are based on the number of responses to specific question items, with Gen potentially ranging from 0 to 40 ; and $\mathrm{Si}, 0$ to 70 . The mean values for Age in columns (5) through (8) are based on rank sorting for the MAO subject groups.

as well as by gender. Table 4 presents a summary of the group means of these parameters and of the statistics testing the differences across various groups. The dependent variable $(\mathrm{Y})$ used in the comparison is reported in column (1) of the table, and the biochemical-psychometric independent variable $(\mathrm{X})$ forming the two rank-ordered groups within each gender is listed in column (2). The mean values of each of the dependent variables as well as the number of observations are reported for each group on columns (3) through (5) and (9) through (10). Columns (6) and (12) provide F-statistics using analysis of variance (ANOVA) based on group type $(\mathrm{X})$ within male and female samples, and column (15) provides F-tests for differences across these groups based on sex (S). Columns (8) and (14) provide chi-squared $\left(\chi^{2}\right)$ statistics based on the 


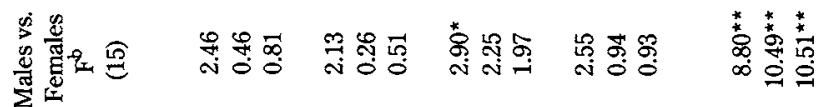

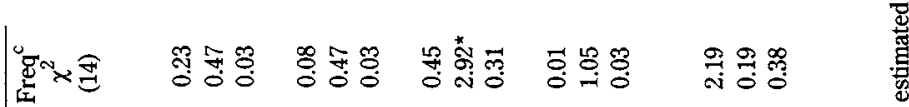

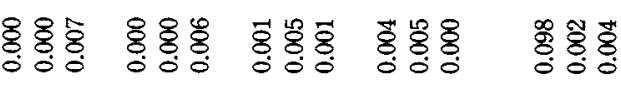

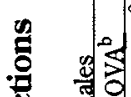

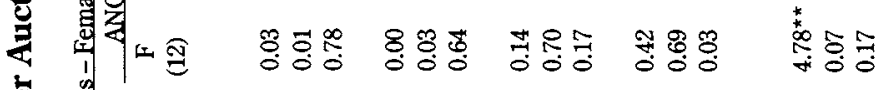

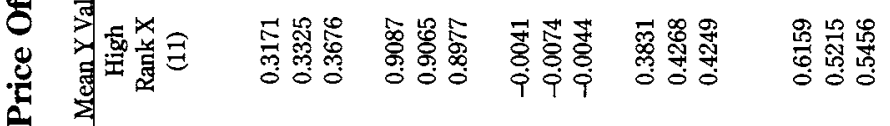

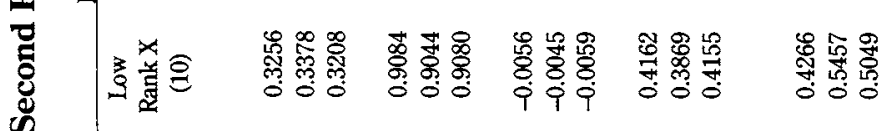

-

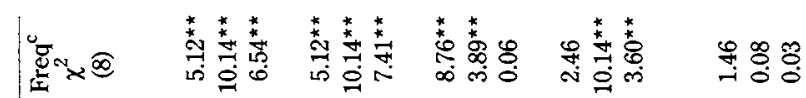
空

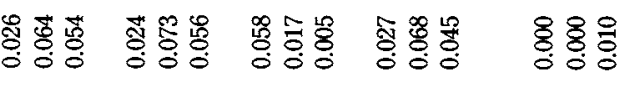

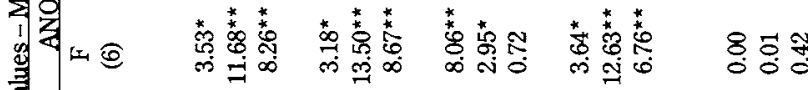

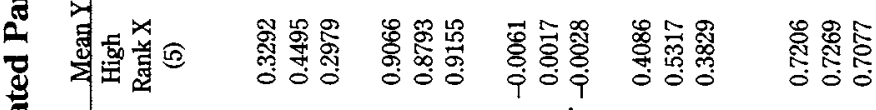

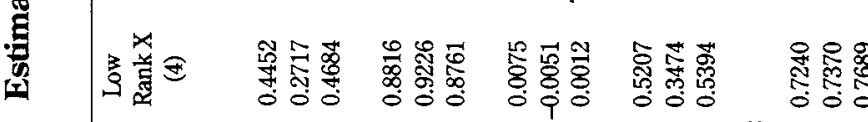

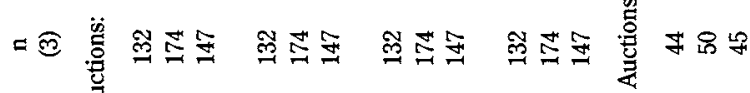

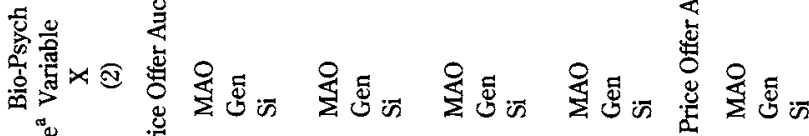

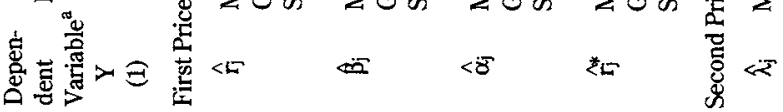


frequency distribution within a two-way contingency table for low and high ranks of both $\mathrm{X}$ and $\mathrm{Y}$ for males and females.

If neurochemical activity plays a role in determining economic preferences, one would expect higher $\hat{\mathrm{r}}_{\mathrm{j}}$ values from the first price auction (i.e., less risk averse or more risk preferring) for individuals with lower levels of MAO, higher Gen scores, and lower Si scores. Moreover, males should tend to have higher $\hat{r}_{j}$ values than females. From Table 4 , this relation is strongly supported within the male subject pool and across males and females based on $\mathrm{F}$ and $\chi^{2}$ statistics. Within the female sample, however, there is no evidence of a difference between MAO, Gen, and Si groups.

Although not significant at conventional statistical levels, it may be noted that females tend to be more risk averse than males, as evidenced by the lower mean values of $\hat{r}_{j}$. The behavioral differences between males and females in this market institution may be the result of differences in MAO levels across the two groups. The hypothesis that males, on average, behave in a less risk-averse fashion relative to females is a joint hypothesis-the behavior may be related to these differences in MAO or may be related to differences in socialization experiences.

Included within the set of dependent variables in Table 4 is the intercept term, $\hat{\alpha}_{\mathrm{j}}$, from the regression in equation (9). ${ }^{10}$ This term has previously been identified by Cox, et. al. (1987) as potentially having economic significance for a generalized first price bidding model. Specifically, the intercept term in (9) may be capturing a monetary equivalent of the utility of winning an auction and is thus relevant for consideration as a parameter characterizing some form of preferences. ${ }^{11}$ From the analysis of this term in Table 4, it is found that there is a significant difference across the rank groups in males for MAO and Gen based on $\mathrm{F}$ and $\chi^{2}$ statistics, and the $\chi^{2}$ statistic indicates a difference in the Gen groups for females. In addition, there is a significant difference between males and females for MAO as the rank variable.

As set out in Appendix A, the equilibrium bid function in (7) is only valid for $b_{j} \leq \bar{b}$. The parameters $\hat{\alpha}_{j}$ and $\hat{r}_{j}$ examined in Table 4 were estimated from

${ }^{10}$ The $\hat{\alpha}_{\mathrm{j}}$ terms have been normalized on the unit (resale value) interval in order to compare the intercepts from regressions for auctions with $n=4$ and $n=6$ bidders.

${ }^{11}$ The non-zero intercept terms may, alternatively, be capturing a bias from imposing a linear regression model (Nash bidding) on non-linear bidding behavior. 
the regression in (9) using only bids meeting this condition. As an additional analysis of the first price auction data, the regressions in (9) were re-estimated using all observations. Denoted as $\hat{r}_{j}^{*}$ in the table, the results from these regressions are similar to those for $\hat{r}_{j}$, with the exception that the mean values for the two female subgroups now vary in a direction comparable to the male subgroups for MAO and Gen, although not significantly different.

Taken as a whole, the first price auction parameters exhibit a significant dependency on the measures of neurochemical activity. Consistent with the original hypothesis, high MAO levels in male subjects are associated with more risk-averse behavior. There is also weak evidence of economic preferences in females having a similar dependency. Further, females tend to be more risk averse than males, which is consistent with the higher average MAO levels in females.

It should be noted at this point that there are several factors contributing to the low $R^{2}$ values shown in Table 4 . Most notably, the subject population employed in this study was of the same approximate age, making it more difficult to establish a biochemical correlation to economic preferences. As discussed earlier, the biochemical and psychological traits that are the focus of this study have an important age dependency. MAO levels increase with age as sensation seeking, impulsivity, and extroversion decrease. By limiting the subject group to a homogeneous age class, the tests have been biased against finding a biochemical relationship. Nonetheless, significant cross-sectional differences in economic behavior have been defined using one measure of neurochemical activity.

As an additional examination of the neurochemical hypothesis, Table 4 also presents the risk aversion estimates from the second price offer auctions. Specifically, the mean $\hat{\lambda}_{j}$ estimates are reported from the regression in (14), in which the intercept terms are constrained to equal $\ln (w)$. Using this measure, one would expect lower $\hat{\lambda}_{j}$ values for individuals with lower levels of MAO, higher Gen scores, and lower Si scores. In this market institution, this relation holds for females with a significant difference for MAO as the rank variable. For males, there is virtually no difference in $\hat{\lambda}_{j}$ estimates for any of the biochemical-psychometric rank variables. Based on the magnitude of the $\hat{\lambda}_{j}$ coefficients, inferred $\hat{\lambda}_{j}$ values are greater than 1.00 , implying risk-seeking behavior.

It should be noted that this risk-seeking behavior is generally consistent with the second price auction behavior documented by Kagel, Harstad, and 
Levin (1987). That is, market prices tend to exceed the predicted prices of the dominant strategy equilibrium in this market institution. Note the difference in $\hat{\lambda}_{j}$ estimates across males and females. Males exhibit more risk aversion (less risk seeking) for the CRRA parameterization than females, in contrast to the first price auction results and the biochemical hypothesis. As mentioned earlier, however, it is impossible to separate MAO effects between males and females from socialization effects. This limitation may be particularly relevant for the second price auction data, because these were obtained in an open classroom experiment with participants aware of the identity of winners and losers in each auction. It may be the case that such an environment elicits different aggregate behavior from males and females because of socialization experiences. What are perhaps more important in the second price auction data, therefore, are the within-gender differences in behavior. At least for females, such differences in behavior appear to be related to differences in platelet MAO. Moreover, these differences generally support a relation of increasing risk aversion (decreasing risk preference) for increasing levels of MAO.

\section{Experimental Results: Groups}

The results presented thus far are based on risk-aversion parameters estimated for each individual subject. As an alternative, estimates may be made for each group as a whole. Although no theoretical basis exists for such aggregation, it does provide statistical means for comparing behavioral differences across groups. For the first price auction, the analysis at the group level was made by modifying the regression in (9) to include dummy intercept and slope variables reflecting the group type. Specifically, dummy variables were included in the regression to distinguish between males and females, biochemical-psychometric rank level, and auctions involving $n=4$ and $n=6$ bidders. This regression across $\mathrm{N}$ subjects and $\mathrm{T}_{\mathrm{F}}$ auctions is represented by:

$$
\begin{aligned}
b_{j t}= & \alpha_{0}+\alpha_{1}\left(\delta_{j \mathrm{j}}^{\mathrm{s}}\right)+\alpha_{2}\left(\delta_{\mathrm{j} t}^{\mathrm{x}}\right)+\beta_{0}\left(\mathrm{v}_{\mathrm{jt}}\right)+\beta_{1}\left(\delta_{\mathrm{jt}}^{\mathrm{n}} \mathrm{v}_{\mathrm{jt}}\right)+\beta_{2}\left(\delta_{\mathrm{jt}}^{\mathrm{s}} \mathrm{v}_{\mathrm{jt}}\right) \\
& +\beta_{3}\left(\delta_{\mathrm{jt}}^{\mathrm{x}} \mathrm{v}_{\mathrm{jt}}\right)+\varepsilon_{\mathrm{jt}}
\end{aligned}
$$

where:

$\delta_{\mathrm{ft}}^{\mathrm{s}}=0$ (female); 1 (male), 
$\delta_{\mathrm{jt}}^{\mathrm{x}}=0$ (low-rank bio/psych group); 1 (high-rank group), and

$\delta_{j \mathrm{t}}^{\mathrm{n}}=0(\mathrm{n}=4) ; 1(\mathrm{n}=6)$.

With MAO as the group rank variable $\delta^{\mathrm{x}}$, over 6,000 first price auctions were available from the experiment. Table 5 presents the results of the estimation of (15) with these data. Notice that intercept and slope dummy variables indicating the gender and MAO group type are all significant. The low-MAO group tends to bid lower for a given resale value, $v$, than the highMAO group (i.e., the low-MAO group is less risk averse). Males also bid in a less risk-averse fashion. The low-MAO groups and males have larger (positive) intercepts than the high-MAO groups and females. Similar results are obtained using Gen and $\mathrm{Si}$ as the group-type independent variables.

\section{TABLE 5}

\section{First Price Auction Regressions}

\begin{tabular}{|c|c|c|c|c|c|c|}
\hline$\alpha_{0}$ & $\alpha_{1}$ & $\alpha_{2}$ & $\beta_{1}$ & $ß_{2}$ & $\beta_{3}$ & $\mathrm{R}^{2}$ \\
\hline \multicolumn{7}{|l|}{$\delta^{\mathrm{x}}=\mathrm{MAO}$} \\
\hline $\begin{array}{l}0.0517 \\
(1.41)\end{array}$ & $\begin{array}{c}0.0659 \\
(1.68)^{\star}\end{array}$ & $\begin{array}{cc}-0.0740 & 0.8842 \\
(-1.89)^{\star} & (164.93)^{\star \star}\end{array}$ & $\begin{array}{c}0.0342 \\
(9.55)^{\star \star}\end{array}$ & $\begin{array}{l}-0.0114 \\
(-2.81)^{\star \star}\end{array}$ & $\begin{array}{c}0.0106 \\
(2.61)^{\star \star}\end{array}$ & 0.972 \\
\hline \multicolumn{7}{|l|}{$\delta^{\mathrm{x}}=\mathrm{Gen}:$} \\
\hline$\frac{-0.0771}{(-2.29)^{\star \star}}$ & $\begin{array}{c}0.0880 \\
(2.47)^{\star \star}\end{array}$ & $\begin{array}{cc}0.0855 & 0.9058 \\
(2.41)^{\star \star} & (184.93)^{\star \star}\end{array}$ & $\begin{array}{c}0.0347 \\
(10.63)^{\star \star}\end{array}$ & $\begin{array}{l}-0.0116 \\
(-3.13)^{\star \star}\end{array}$ & $\begin{array}{l}-0.0278 \\
(-7.48)^{\star \star}\end{array}$ & 0.969 \\
\hline \multicolumn{7}{|l|}{$\delta^{\mathbf{x}}=\mathrm{Si}:$} \\
\hline $\begin{array}{l}0.0508 \\
(1.33)\end{array}$ & $\begin{array}{c}0.0703 \\
(1.74)^{\star}\end{array}$ & $\begin{array}{cc}-0.1169 & 0.8739 \\
(-2.91)^{\star \star} & (158.23)^{\star \star}\end{array}$ & $\begin{array}{c}0.0348 \\
(9.47)^{\star \star}\end{array}$ & $\begin{array}{l}-0.0111 \\
(-2.63)^{\star \star}\end{array}$ & $\begin{array}{c}0.0263 \\
(6.28)^{\star \star}\end{array}$ & 0.967 \\
\hline
\end{tabular}

Note: Significance is reported at the 0.05 level $\left(^{\star \star}\right)$ and the 0.10 level $\left(^{\star}\right)$. 
For the second price offer auction data, a similar group estimation methodology may be applied. Augmenting (14) to allow for aggregate differences across gender and biochemical-psychometric rank levels, the regression model for $T_{S}$ auctions and $\mathrm{N}$ subjects (a total of over 800 auctions) becomes:

$$
\begin{aligned}
\ln \left(\mathrm{b}_{\mathrm{j} t}\right)= & \gamma_{0}(\ln (\mathrm{w}))+\gamma_{1}\left(\delta_{\mathrm{j}}^{\mathrm{s}} \ln (\mathrm{w})\right)+\lambda_{0}\left(\ln \left(\mathrm{p}_{\mathrm{t}}\right)\right)+\lambda_{1}\left(\delta_{\mathrm{jt}}^{\mathrm{s}} \ln (\mathrm{pt})\right) \\
& +\lambda_{2}\left(\delta_{\mathrm{j} t}^{\mathrm{x}} \ln \left(\mathrm{p}_{\mathrm{t}}\right)\right)+\varepsilon_{\mathrm{jt}}
\end{aligned}
$$

where dummy variables are defined in (15). Table 6 contains results for the estimation of (16), for the cases in which the intercept term is not constrained to equal $\ln (w)$ and for the intercept restriction $\left(\gamma_{0}=1.00\right.$ and $\left.\gamma_{1}=0\right)$. In both cases, there is a significant difference in bidding behavior between low and high levels of MAO and between males and females. High levels of MAO are once again associated with more risk-averse behavior (less risk-preferring). As discussed earlier, however, males in this market institution are, on average, bidding in a more risk-averse (less risk-preferring) fashion than are females, which may be caused by socialization effects. Regressions with $\mathrm{Gen}$ and $\mathrm{Si}$ as the $\delta^{x}$ rank variable yield insignificant coefficients.

As a final analysis of the relation between neurochemical processes and economic risk aversion, the lottery pair choices (from Table 1) were examined via a logistic regression (logit) model. ${ }^{12} \mathrm{~A}(0,1)$ dependent variable modeled the P-bet selection in each lottery pair; that is, a 0 indicated a D-bet was chosen and $\mathrm{a} 1$ indicated a P-bet. For the entire set of $\mathrm{T}_{\mathrm{L}}$ lottery pairs and $\mathrm{N}$ subjects (over 1,300 observations), the regression function used to describe the probability of a P-bet selection was:

$$
\begin{aligned}
z_{j t}= & \alpha_{0}+\alpha_{1}\left(\delta_{j t}^{s}\right)+\alpha_{2}\left(\delta_{j t}^{x}\right)+\alpha_{3}\left(\delta_{j t}^{s} \delta_{j t}^{x}\right)+\beta_{0}\left(r_{p t}\right) \\
& +\beta_{1}\left(\delta_{j t}^{s} r_{p t}\right)+\beta_{2}\left(\delta_{j t}^{x} r_{p t}\right)+\varepsilon_{j t}
\end{aligned}
$$

${ }^{12}$ Lottery pair (6) was omitted from the analysis so as not to overweight pairs with $r_{p}$ values equal to 1.00 and so that all pairs included had positive expected values. 


\section{TABLE 6}

\section{Second Price Offer Auction Regressions}

\begin{tabular}{|c|c|c|c|c|c|}
\hline \multicolumn{3}{|c|}{$\ln \left(b_{j t}\right)=\gamma(\ln (w))+\gamma 1\left(\delta_{j t}^{s} \ln (w)\right)+\lambda$} & $\lambda_{0}\left(\ln \left(p_{t}\right)\right)+\lambda_{1}\left(\delta_{j t}^{s} \ln \left(p_{t}\right)\right)$ & \multirow{2}{*}{$\begin{array}{c}+\lambda_{2}\left(\delta_{\mathrm{jt}}^{\mathrm{x}} \ln \left(\mathrm{p}_{\mathrm{t}}\right)\right. \\
\lambda_{2}\end{array}$} & \multirow{2}{*}{$\begin{array}{l}+\varepsilon_{j \mathrm{jt}} \\
\\
\mathrm{R}^{2}\end{array}$} \\
\hline 10 & $\gamma_{1}$ & $\lambda_{0}$ & $\lambda_{1}$ & & \\
\hline \multicolumn{6}{|l|}{$\delta^{\mathrm{x}}=\mathrm{MAO}$} \\
\hline $\begin{array}{c}0.9713 \\
(-5.97)^{\star \star}\end{array}$ & $\begin{array}{r}0.1120 \\
(1.76)^{*}\end{array}$ & $\begin{array}{c}0.2844 \\
(6.93)^{\star \star}\end{array}$ & $\begin{array}{c}0.2561 \\
(5.73)^{\star \star}\end{array}$ & $\begin{array}{c}0.0005 \\
(3.92)^{\star \star}\end{array}$ & 0.995 \\
\hline $\begin{array}{c}1.0000 \\
(-6.44)^{\star \star}\end{array}$ & 0.0000 & $\begin{array}{c}0.4245 \\
(12.27)^{\star \star}\end{array}$ & $\begin{array}{c}0.1966 \\
(6.52)^{\star \star}\end{array}$ & $\begin{array}{c}0.0005 \\
(3.83)^{\star \star}\end{array}$ & 0.387 \\
\hline \multicolumn{6}{|l|}{$\delta^{\mathbf{x}}=$ Gen: } \\
\hline $\begin{array}{c}0.9712 \\
(-5.41)^{\star \star}\end{array}$ & $\begin{array}{l}0.0458 \\
(0.67)\end{array}$ & $\begin{array}{c}0.4122 \\
(9.42)^{\star \star}\end{array}$ & $\begin{array}{c}0.2205 \\
(4.59)^{\star \star}\end{array}$ & $\begin{array}{l}-0.0001 \\
(-0.72)\end{array}$ & 0.994 \\
\hline $\begin{array}{c}1.0000 \\
(-6.88)^{\star \star}\end{array}$ & 0.0000 & $\begin{array}{c}0.5529 \\
(15.31)^{\star \star}\end{array}$ & $\begin{array}{c}0.1961 \\
(6.05)^{\star \star}\end{array}$ & $\begin{array}{l}-0.0001 \\
(-0.70)\end{array}$ & 0.320 \\
\hline \multicolumn{6}{|l|}{$\delta^{\mathrm{x}}=\mathrm{Si}$} \\
\hline $\begin{array}{c}0.9746 \\
(-4.42)^{\star \star}\end{array}$ & $\begin{array}{l}0.0059 \\
(0.08)\end{array}$ & $\begin{array}{c}0.3803 \\
(8.17)^{\star \star}\end{array}$ & $\begin{array}{c}0.2155 \\
(4.16)^{\star \star}\end{array}$ & $\begin{array}{c}0.0001 \\
(0.78)\end{array}$ & 0.994 \\
\hline $\begin{array}{c}1.0000 \\
(-6.13)^{\star \star}\end{array}$ & 0.0000 & $\begin{array}{c}0.5045 \\
(13.30)^{\star \star}\end{array}$ & $\begin{array}{c}0.2122 \\
(6.10)^{\star \star}\end{array}$ & $\begin{array}{l}0.0001 \\
(0.76)\end{array}$ & 0.326 \\
\hline
\end{tabular}

Note: Significance is reported at the 0.05 level $\left(^{\star \star}\right)$ and the 0.10 level $\left({ }^{\star}\right)$. 
where the dummy variables are defined as in (15). ${ }^{13}$ The parameter estimates from this model are presented in Table 7. Because probability is increasing in $z$, the estimated logit function indicates that the probability of making a P-bet choice is increasing in $r_{p}$ values for the lottery pairs. Moreover, this probability of selecting a P-bet decreases for the low-MAO groups and for males relative to females. Both of these relations are consistent with the risk-aversion results obtained from the other market institutions.

Using the inverse logistic transformation, the probability of making a P-bet selection may be estimated for a range of values for the independent variables. Figure 10 provides a plot of these estimated probabilities for the various subject groups across the set of $r_{p}$ values used in the lottery pairs. Immediately evident are the different probability functions for males with differing levels of platelet MAO. Low-MAO males have a lower probability of making a P-bet selection than high-MAO males for all $r_{p}$ values, and this difference in behavior is statistically significant. Low-MAO females exhibit the same behavior for large $r_{p}$ values and an opposite behavior for small $r_{p}$ values (not a significant difference for MAO but significant for Gen). ${ }^{14}$

For each of the groups depicted in Figure 10, an estimate of aggregate risk aversion may be obtained by inferring the $r_{p}$ value at the point of indifference between a P-bet and a D-bet (i.e., where the probability of selecting a P-bet is equal to 0.5). For males with lower levels of MAO, this estimated $r_{p}$ value is equal to 1.12 , and for males with higher levels of MAO, 1.02. For females, the estimated value is 1.02 for both high and low levels of MAO. Thus, at least for males in this institution, lower levels of platelet MAO are associated with less risk-averse (more risk-seeking) behavior. The overall behavioral differences for the groups, males and females, across all lotteries represented by the probability functions, are perhaps as important as these point estimates.

${ }^{13}$ For $p_{j t}$ defined as the probability of making a P-bet selection, the logit regression model is specified as:

$$
\mathrm{p}_{\mathrm{jt}}=\mathrm{F}\left(\mathrm{z}_{\mathrm{jt}}\right)=\mathrm{F}\left(\alpha+\beta \mathrm{X}_{\mathrm{jt}}\right)=\frac{1}{1+\mathrm{e}^{-\mathrm{z}_{\mathrm{jt}}}}=\frac{1}{1+\mathrm{e}^{-\left(\alpha+\beta \mathrm{X}_{\mathrm{jt}}\right)}}
$$

${ }^{14}$ Estimation of logit regressions for males and females separately indicate significance for the $r_{p}$ variable in both groups and significance for the MAO slope and intercept dummy, $\delta_{x}$, for males only. Using Gen as the rank variable, however, differences within the male and female groups are both significant and the functions from this regression model are virtually identical to those presented in Figure 10. The Si variable shows significance for the male group. 


\section{TABLE 7}

\section{Logit Regressions of Lottery Pair Choices}

\begin{tabular}{|c|c|c|c|c|c|c|c|}
\hline$\alpha_{0}$ & $\alpha_{1}$ & $\alpha_{2}$ & $\alpha_{3}$ & $B_{0}$ & $\beta_{1}$ & $ß_{2}$ & $\chi^{2}$ \\
\hline \multicolumn{8}{|l|}{$\delta^{\mathrm{x}}=\mathrm{MAO}$} \\
\hline-3.3503 & -1.0375 & -1.1643 & 0.4084 & 3.2983 & 0.6271 & 1.1171 & \\
\hline$(36.44)^{\star \star}$ & $(2.21)$ & $(2.83)^{\star}$ & $(2.94)$ & $(38.26)^{\star \star}$ & $(0.90)$ & $(2.84)^{\star}$ & $204.44^{\star \star}$ \\
\hline \multicolumn{8}{|l|}{$\delta^{\mathbf{x}}=$ Gen: } \\
\hline-4.4482 & -1.0644 & 1.2352 & -0.3965 & 4.4029 & 0.9665 & -1.1966 & \\
\hline$(57.35)^{\star \star}$ & $(2.56)$ & $(3.36)^{\star}$ & $(2.99)^{\star}$ & $(59.63)^{\star \star}$ & $(2.30)$ & $(3.43)^{\star}$ & $235.36^{\star \star}$ \\
\hline \multicolumn{8}{|l|}{$\delta^{\mathrm{x}}=\mathrm{Si}$} \\
\hline-3.7822 & -0.9795 & -0.7472 & -0.0023 & 3.5488 & 0.8857 & 0.9569 & \\
\hline$(38.19)^{\star \star}$ & (1.79) & (1.06) & $(0.00)$ & $(36.86)^{\star \star}$ & (1.63) & (1.90) & $218.03^{\star \star}$ \\
\hline
\end{tabular}

Note: Significance is reported at the 0.05 level $\left(^{\star \star}\right)$ and the 0.10 level $\left(^{\star}\right)$.

Whereas the two female MAO groups have similar risk-aversion estimates, they do display aggregate differences across the entire set of lotteries, and these differences are significantly related to one of the psychometric variables which is correlated with neurochemical activity.

The results presented provide considerable support for a neurochemical correlation to economic preferences and risk aversion. Across the various market institutions employed, there is evidence of a biochemical-based difference in economic behavior for both males and females. 


\section{FIGURE 10}

\section{Lottery Pair Preferences for Biologically Defined Groups}

Male Subjects

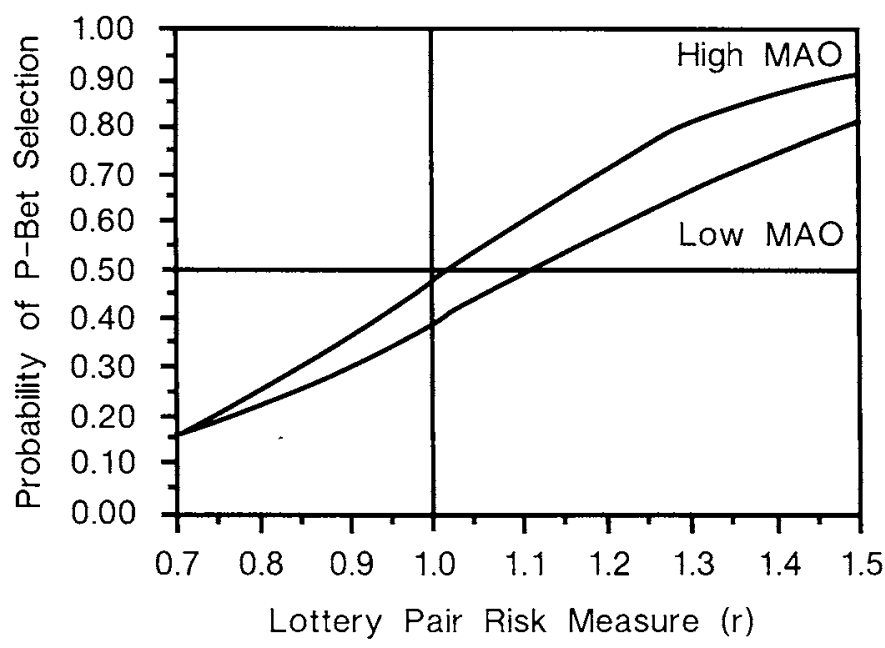

Female Subjects

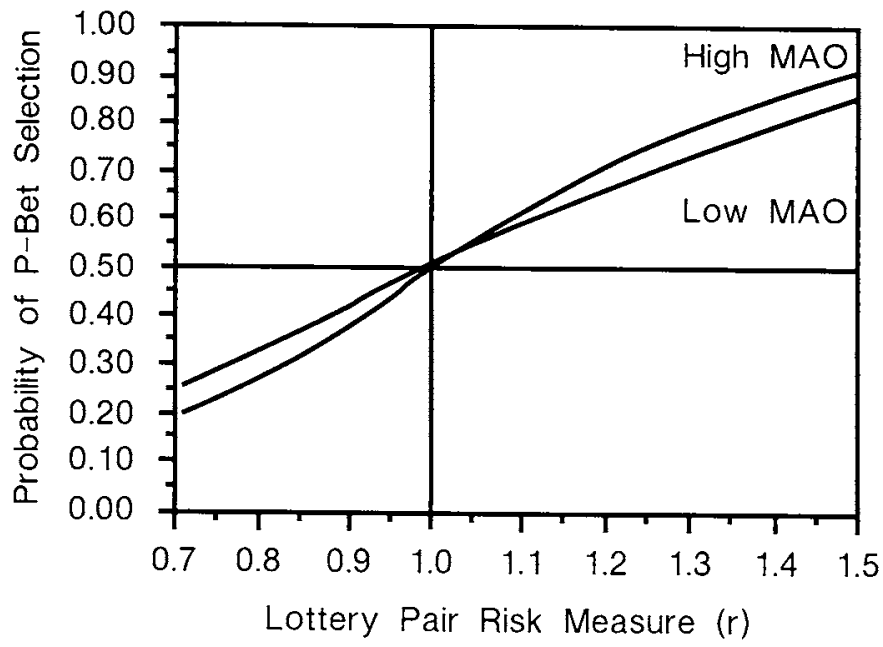




\section{Summary and Implications}

As it has evolved over the past two decades, the most prudent approach to the asset allocation process requires that a money manager be able to assess and integrate two distinct sets of economic data. First, a collection of capital market variables must be evaluated across the available set of securities so that expectations about future performance may be formed. Second, once the array of feasible portfolio choices has been assembled, an optimal selection may be made only after assessing the relevant investor's attitudes toward bearing risk. Although few would argue that this latter dimension is in any way the least important of the two, it is nevertheless true that the evaluation of financial risk tolerance has received far less attention from practitioners and academics alike. The primary factor contributing to this deficiency appears to be a general lack of understanding of risk-aversion determinants. This, in turn, has led to our current inability to quantify accurately this crucial individualspecific characteristic.

This study has reviewed and extended what is presently known about the way investors form their preferences in the face of uncertain economic conditions. Our survey of existing risk-tolerance assessment techniques showed that a great deal of effort has gone into characterizing the physiological and psychological makeup of the investor. Despite there being little agreement within the money management profession on the proper method for deploying this knowledge, a number of general associations have been established. Of particular interest in the present context are studies that link an investor's risk tolerance to physical factors (e.g., age). For all the sophistication and creativity that has been brought to bear on this problem, the critical issues of why individuals with similar characteristics have different preferences and how 
these preferences might be altered over time remain unaddressed. For this reason, we have concentrated our empirical analysis on identifying some of the more elemental influences forming the foundation of an individual's decision making process.

The major purpose of this study has been to develop a new perspective of risk aversion with the hope of laying the groundwork for future research in this area and for the development of improved risk-tolerance assessment procedures for individual investors. The preliminary investigations reported herein document what may well be a fundamental link between economic measures of risk aversion and certain biological and psychological characteristics. Specifically, we have shown that for our subject group, individuals with neurochemical activity characterized by lower levels of the enzyme monoamine oxidase (MAO) tended to be more willing to accept economic risk. Conversely, higher levels of this enzyme appeared to be associated with more risk-averse behavior.

This biological link to economic behavior was determined using 183 individual subjects participating in an extensive series of economic, psychological, and biochemical tests designed to identify possible determinants of economic preferences and financial risk tolerances. Under the assumption that individuals exhibit constant relative risk aversion (CRRA), estimates of the willingness to accept financial risk were obtained from observations of bidding behavior in computerized first price sealed bid auctions using newly developed theoretical models. In addition, similar CRRA parameters were inferred from bidding behavior in second price offer auctions and from the choices made among risky lottery pairs. These economic measures of risk aversion were then compared to psychological measures of personality and to the level of MAO obtained from blood plasma samples. $\mathrm{MAO}$, as an enzyme involved in regulating the neurochemical transmission processes of the brain, was found to play a significant role in explaining differences in individuals' behavior in these economic decision environments.

Whereas a biochemical basis for economic behavior represents a new research frontier, it is supported by other research relating behavioral traits to biological factors. Psychological and medical research in areas generally described as behavioral biology or behavioral physiology has established the relation between certain individual personality characteristics and various components of the complex set of neurochemical systems (MAO being one of many such components). These personality traits are broadly defined as 
sensation seeking, impulsivity, and extroversion. Individuals who have high sensation- seeking tendencies and who are impulsive and extroverted have, on average, neurochemical activity that is measurably different from that of individuals who are less so. It is also true that these behavioral traits, which may be ascertained through psychological testing, have many parallels with economic notions of financial risk-taking. For example, thrill- and adventureseeking (a form of sensation seeking) is a trait which reflects an individual's propensity to engage in risky activities and sports (e.g., sky diving and mountain climbing) and some aspects of risk-taking within those activities. Controlling for other factors, thrill- and adventure-seeking individuals have lower MAO levels, which correspond to those of individuals who are also willing to take financial risks.

What is particularly interesting about such personality traits and their biochemical correlates is the manner in which they change with age. Sensation seeking has been found to decrease with age, whereas MAO levels increase. All of these findings are consistent with empirically observed characteristics of individuals' perceptions of risk and the riskiness of their portfolio holdings. Studies have found that investors with higher risk tolerances are typically younger. Moreover, individuals' portfolios tend to be less risky as they get older. Thus, the traditional view of a life-cycle pattern of risk aversion (i.e., increasing risk aversion with age) is consistent with both observed investment behavior and with the characteristics of these psychological and biochemical traits. It appears, therefore, that there may be some biological mechanism that tends to make individuals more averse to risk as they age, both in terms of financial risk and other forms of risk. This is not too surprising, as the levels of MAO and other components of the neurological system have been found to have a strong genetic influence.

In keeping with this body of behavioral research, this study demonstrates that, along with neurochemical activity, financial risk tolerance is significantly related to personality traits such as sensation seeking and extroversion. Individuals who exhibit higher degrees of various forms of sensation seeking and those who are less introverted are more willing to accept financial risk. Thus, there appears to be a consistent biological and behavioral framework that provides an attractive vantage point from which to view economic behavior and its assessment.

Certainly, these biological and psychological connections to financial risk tolerances have important implications. From a theoretical perspective, this 
research sheds new light on a continuing debate between psychologists and economists that centers on individual decision making. Psychologists often argue that individuals' choices are primarily determined by factors unique to the particular decision setting, whereas economists assume that there is some individual-specific mechanism playing a common role in all economic decisions. The fact that there are biological and psychological factors underlying economic behavior across different individuals lends support for economists' view of a common choice and valuation process.

From a more practical standpoint, a biological and psychological basis for economic preferences may allow for the development of improved methods to assess an individual's economic risk aversion. Client-specific risk tolerances could be assessed using improved psychological measures known to be correlated both with biochemical and economic attributes. The existence of this biological thread also may provide insights into the heterogeneity of individuals' economic preferences and risk aversion and how these differences change over time. The extent of these differences and their intertemporal properties play an important role in the asset allocation process. Although this entire line of research is still in its infancy, the prospects for new developments and new insights into economic behavior are very exciting. 


\section{Appendix A}

\section{First Price Sealed Bid Auction}

In the first price sealed bid auction, each of $n$ bidders submits a bid for a single unit of a commodity with the commodity being awarded to the highest bidder at a price equal to the highest bid. If the objective of bidder $j$ is to maximize the expected utility of income, then $j$ 's bid, $b_{j}$, will be chosen to maximize:

$$
E\left[u_{j}\left(b_{j}\right)\right]=G_{j}\left(b_{j}\right) u_{j}\left(v_{j}-b_{j}\right)
$$

where $v_{j}$ is the value of the commodity to $j$ (known with certainty) and $G_{j}\left(b_{j}\right)$ is the subjective probability that $b_{j}$ will be the highest bid.

The generalized non-cooperative equilibrium bid function for (A1) has been developed by Cox, Roberson, and Smith (1982) and Cox, Smith, and Walker (1985a, 1985b, and 1987) for heterogeneous and risk-averse bidders under the assumption that agents exhibit constant relative risk aversion (CRRA). That is, the utility function in (A1) is assumed to be of the form:

$$
u_{j}\left(b_{j}\right)=\left(v_{j}-b_{j}\right)^{r j}
$$

where $\left(1-r_{j}\right)$ is individual j's Arrow-Pratt CRRA parameter $\left(r_{j}=1\right.$ implying risk neutrality). If $v_{j}$ is assumed to be drawn from a uniform distribution on the interval $(0, \vec{v})$ and $r_{j}$ is drawn from the distribution with a cumulative distribution function $F\left(r_{j}\right)$ on $(0, \bar{r})$ for $\bar{r} \geq 1$, then the equilibrium bid function is given by:

$$
b_{j}=\left[\frac{n-1}{n-1+r_{j}}\right] v_{j}
$$

where $b_{j} \leq \bar{b} \equiv\left[\frac{n-1+\bar{r}}{n-1}\right] \bar{v}$ (i.e., $b_{j}$ is less than or equal to the maximum bid for the least risk-averse bidder in the group). There is no closed-form solution for $b_{j}>\bar{b}$. It is important to note that the Holt (1980) bidding model is a special case of (A3) under the additional restriction that all bidders are homogeneous (i.e., they behave as if they all have the same equilibrium bid 
function). If all bidders are assumed to be risk-neutral, the Vickrey (1961) equilibrium bid function obtains.

As Cox, et al. have noted, the linear bid function in (A3) is independent of other bidders' preferences making this market institution attractive to assess an individual's risk-aversion characteristics. In particular, (A3) allows for the estimation of the CRRA parameter using a sequence of auctions. Under the assumption that the least risk-averse bidder in the group is risk-neutral $(\bar{r}=1)$, the regression hypothesis for such estimation is:

$$
b_{j t}=\alpha_{j}+\beta_{j j} v_{j t}+\varepsilon_{j t} \quad t=1, \ldots, T
$$

for $v_{j t} \leq \bar{v}_{j} \equiv\left[\frac{n-1+r_{j}}{n}\right] \bar{v}$. The regression coefficients $\alpha_{j}$ and $\beta_{j}$ are parameters capturing an individual's bidding behavior across $T$ auctions with $b_{j}$ being proportional to the Arrow-Pratt measure of risk aversion. That is, an estimate of $r_{j}$ using (A3) and (A4) is:

$$
\hat{r_{j}}=\frac{(n-1)\left(1-\hat{\beta}_{j}\right)}{\hat{\beta}_{j}} .
$$

Thus, more risk-averse individuals will tend to have larger values for $\hat{b}_{j}$ (lower values for $\hat{r}_{j}$ ). Note that the $\hat{r}_{j}$ estimate is a nonlinear transformation of the $b_{j}$ coefficient from (A4), and as such, $\hat{r}_{j}$ is a biased estimator under OLS. To avoid potential problems arising from any differences in these parameter estimates, both $\hat{r}_{j}$ and $\hat{b}_{j}$ are included in all analyses. Thus, equations (A4) and (A5) provide the basis for assessing individuals' risk aversion. 


\section{Appendix B}

\section{Lottery Pair Instructions}

The experimenters are interested in examining how people make decisions. We have designed a simple choice experiment, and we shall ask you to make decisions in each of several items. Each decision you shall make will involve two bets. If a bet is played, then one ball will be drawn from a bingo cage containing 100 balls numbered from 1 to 100 . Depending upon the nature of the bet, the number drawn will determine whether you lose an amount of money or win an amount of money. Consider, as an example, the bet represented by Figure B-1 below. If you play this bet, you will lose 2,000 francs if the number drawn is less than or equal to 33 , and you will win 16,000 francs if the number drawn is greater than 33 . For the purpose of this experiment, one U.S. dollar is equal to 2,000 francs.

\section{FIGURE B-1}

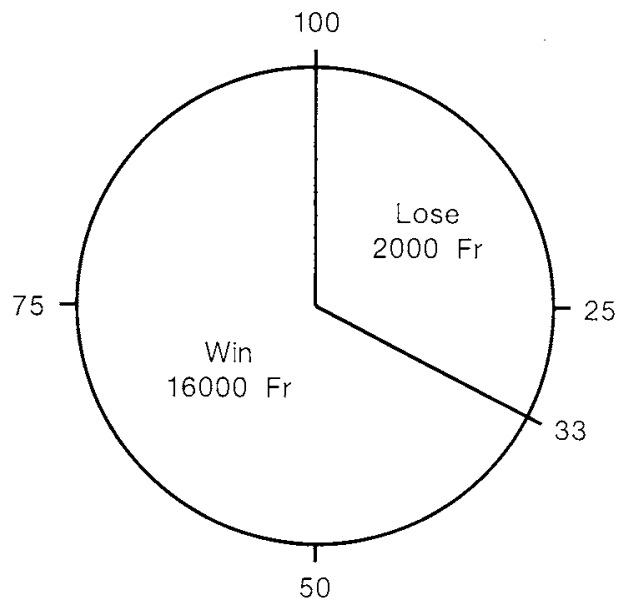

Consider carefully the pairs of bets in Figures 1 through $16 .^{*}$ On your answer sheet, select the bet you would prefer to play by placing a check in the appropriate space. If you do not care which bet you play, merely indicate this in the space provided. At the end of all of the experiments today, one item (i.e.,

*Not shown in this publication. 
one pair of bets) will be chosen at random by drawing a ball from a bingo cage. The bets in the chosen item will then be played. You will be paid an amount depending upon your decision and upon the outcome of the bet in the chosen item. Any amount you win will be added to your earnings, and any amount you lose will be subtracted from your earnings. If on the chosen item you indicated that you did not care which bet was played, then your choice will be determined by a coin toss.

Do you have any questions? 


\section{Appendix C}

\section{Second Price Auction Instructions}

\section{Description of the Experiment}

The experimenters are interested in examining how people make decisions when faced with risky situations. In this experiment, the risky situations will arise in a series of opportunities to buy or sell lottery tickets. Each lottery ticket will carry some chance of causing its owner to win and/or lose a certain amount of money. The outcome of each lottery is determined based on the number obtained in a single draw from a bingo cage containing 100 balls numbered from 1 to 100 . Figure $\mathrm{C}-1$ shows two simple examples of a lottery ticket:
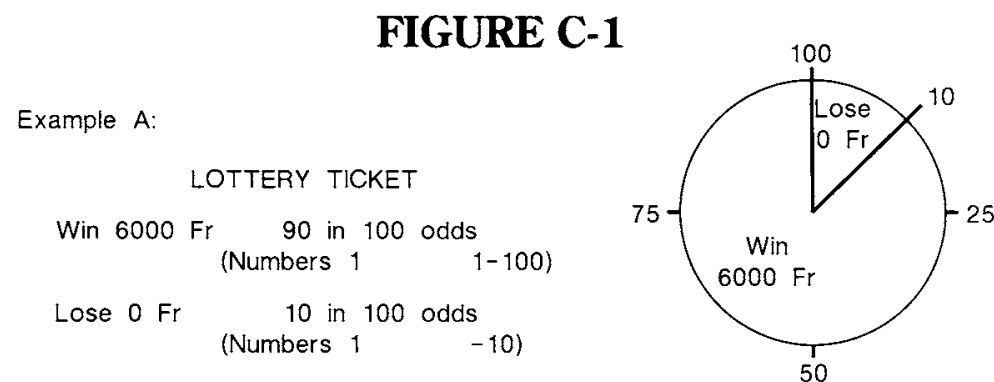

Example $\mathrm{B}$
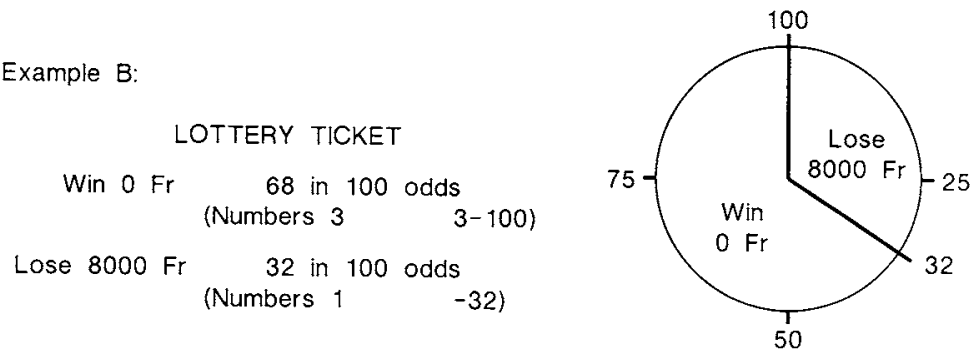

The essential idea of this experiment can be described very simply using these example lottery tickets. Consider Example A which has a 90 in 100 chance of winning 6,000 francs. If you owned the ticket, you might be willing to give up ownership if you were paid some amount to compensate you for forgoing the chance of winning 6,000 francs. If you did not own the ticket, you 
would probably be willing to pay some amount of money to obtain ownership of the lottery ticket.

Now consider the lottery ticket in Example B which carries a 32 in 100 chance of losing 8,000 francs. If you owned this ticket you would probably be willing to pay some amount of money to rid yourself of ownership. If you did not own the ticket, you might be willing to accept ownership if given a payment to compensate for the chance of losing 8,000 francs that the ticket brings.

\section{Description of the Sealed Bid Second Price Auction}

In this experiment, the opportunities to buy and sell these lottery tickets will arise under a special kind of auction, i.e., the sealed bid secondprice auction . By sealed bid we mean that the bids are secret. You formulate and submit your bid not knowing the bids of other bidders. A second price auction is an auction where the individual with the highest bid gets ownership of the item but that individual only pays an amount equal to the second highest bid. The experimenters want you to understand that the best strategy in this auction is to make a bid equal to the maximum value that you are willing to pay for a particular lottery ticket because you will only have to pay an amount equal to the second highest bid. You cannot do better with a different strategy. If you bid less than the maximum value you place on owning the lottery ticket then you may not get the lottery ticket even though the terms of the ticket are attractive to you. If you bid more than your maximum value then you may have to pay a price for it that is higher than the maximum value you actually place on the lottery ticket.

In this experiment, we will also use the second price offer auction. Imagine you were selling some item that you owned in a second price offer auction. The person who submitted the lowest offer would get to sell the item they owned but would receive an amount equal to the second lowest offer. In this auction, the best strategy is to make an offer equal to the minimum value that you would be willing to accept to give up ownership of a particular lottery ticket because you will be paid an amount equal to the second lowest offer. If you make an offer higher than your minimum value, then you may have to retain ownership of your lottery ticket even though you would have been able to sell it at a price attractive to you. If you make an offer lower than your minimum value, then you risk selling your lottery ticket at a price less than the minimum value you actually place on the ticket. 


\section{Experiment Instructions}

If you choose to participate in the experiment, you will receive 4,000 francs and ownership of some lottery tickets like those in Examples A and B. You will then participate in a series of second price and second price offer auctions to buy, sell, accept, or get rid of lottery tickets. Some of these tickets will offer lotteries involving only the chance of winning or losing a stated amount. Other tickets will offer combined chances of winning or losing different amounts. For the purpose of this experiment, one U.S. dollar is equal to 2,000 francs.

After bids are submitted in each second price auction, the appropriate auction price (second highest price) will be collected from the highest bidding individual. A drawing from a bingo cage will then be made to determine the outcome of the lottery. In the case of a second price offer auction, the appropriate offer price (second lowest offer) will be paid to the individual with the lowest offer prior to the lottery. Settlement of the winning or losing lottery ticket(s) will be made in cash based on the outcome of the lottery before moving on to the next auction. In the event of a large number of losses from participating in the experiment, you will be guaranteed the 4,000 francs $(\$ 2.00)$ of starting capital for participating in the experiment (in addition to the $\$ 3.00$ you received for showing up).

Do you have any questions?

\section{Example}

To make sure you fully understand the experiment, the experimenters will run a couple of trial auctions involving the lottery tickets represented in the figures on the next pages (Auctions 0 and 00). In Auction 0, you will be asked to submit a bid equal to the maximum value that you would be willing to pay to obtain ownership of this particular ticket. In Auction 00, it will be assumed that you own this particular lottery ticket. You will then be asked to submit an offer equal to the minimum value that you would be willing to accept in order to give up ownership of this ticket. These auctions are for illustration purposes only and will not involve cash. 


\section{REFERENCES}

Arrow, K 1971. Essays in the Theory ofRisk-Bearing. Chicago: Markham Publishing.

Baker, H. K. and J. A. Haslem. 1974. "Toward the Development of Client-Specified Valuation Models." Journal of Finance 29 (September): 1255-63.

Barnewall, M. M. 1987. "Psychological Characteristics of the Individual Investor." In William G. Droms, ed., Asset Allocation for the Individual Investor. Charlottesville, VA: The Institute of Chartered Financial Analysts.

Battalio, R. C., J. H. Kagel, and D. N. MacDonald. 1985. “Animals' Choices over Uncertain Outcomes." American Economic Review 75 (September): 597-613.

Blume, M. E. and I. Friend. 1978. The Changing Role of the Individual Investor. New York: John Wiley \& Sons.

Brinson, G. P., L. H. Hood, and G. L. Beebower. 1986. "Determinants of Portfolio Performance.” Financial Analysts Journal (July/August): 39-44.

Buchsbaum, M. S. 1971. "Neural Events and the Psychophysical Law." Science 172: 502 .

Condon, K. A. 1982. "Asset Mix Model." In Asset Allocation Decisions in Portfolio Management. Charlottesville, VA: The Institute of Chartered Financial Analysts.

— 1983. "Portfolio Construction: Asset Allocation." In J. L. Maginn and D. L. Tuttle, eds., Managing Investment Portfolios: A Dynamic Process. New York, NY: Warren, Gorham \& Lamont: 261-90.

Cox, J. C., B. Roberson, and V. L. Smith. 1982. "Theory and Behavior of Single Object Auctions." In V. L. Smith, ed., Research in Experimental Economics. JAI Press: 1-43.

Cox, J. C., V. L. Smith, and J. M. Walker. 1984. "Theory and Behavior of Multiple Unit Discriminative Auctions." Journal of Finance 39 (September): 983-1010. 
1985a. "Expected Revenue in Discriminative and Uniform Price Sealed Bid Auctions." In V. L. Smith, ed., Research in Experimental Economics. JAI Press: 183-232.

1985b. "Experimental Development of Sealed Bid Auction Theory: Calibrating Controls for Risk Aversion." Proceedings and Papers of the American Economic Association 75 (May): 160-65.

1987. "Theory and Individual Behavior of First Price Auctions." Working Paper, University of Arizona.

Droms, W. G. 1987. "Investment Risk and the Individual Investor-Part I." In William G. Droms, ed., Asset Allocation for the Individual Investor. Charlottesville, VA: The Institute of Chartered Financial Analysts.

Fielitz, B. D. and F. L. Muller. 1983. “The Asset Allocation Decision." Financial Analysts Journal (July/August): 44-50.

Fouse, W. L. 1982. "Asset Allocation." In Asset Allocation Decisions in Portfolio Management. Charlottesville, VA: The Institute of Chartered Financial Analysts.

Friend, I. and M. E. Blume. 1975. "The Demand for Risky Assets." American Economic Review 65: 900-922.

Fulker, D., S. B. W. Eysenck, and M. Zuckerman. 1980. "A Genetic and Environmental Analysis of Sensation Seeking." Journal of Research in Personality 14: 261-81.

Harless, D. W. 1987. "New Evidence on the Disparity to Pay and Compensation Demanded.” Working Paper, University of Indiana.

Harlow, W. V. 1988. "Economic Preferences and Risk Aversion: An Alternative Perspective." Working Paper, University of Arizona (October).

Hathaway, S. R. and J. C. McKinley. 1951. The Minnesota Multiphasic Personality Inventory (revised edition). New York: Psychological Corp.

Holt, C. A. 1980. "Competitive Bidding for Contracts Under Alternative Auction Procedures." Journal of Political Economy 88 (June): 433-45. 
Kagel, J. H., R. M. Harstad, and D. Levin. 1987. "Information Impact and Allocation Rules in Auctions with Affiliated Private Values: A Laboratory Study." Econometrica 55 (November): 1275-1304.

Kahneman, D. and A. Tversky. 1979. "Prospect Theory: An Analysis of Decision Under Risk." Econometrica 47 (March): 263-91.

Kaiser, R. W. 1987. "The Dynamics of the Investment Decision-Making Process for the Individual Investor-Part I." In William G. Droms, ed., Asset Allocation for the Individual Investor. Charlottesville, VA: The Institute of Chartered Financial Analysts.

LeBaron, D. G. Farrelly and S. Gula. 1989. "Facilitating a Dialog on Risk: A Questionnaire Approach." Financial Analysts Journal (May/June): 19-24.

Lipper, A. M. and M. J. Busby. 1987. "The Traditional Asset Classes." In William G. Droms, ed., Asset Allocation for the Individual Investor. Charlottesville, VA: The Institute of Chartered Financial Analysts.

Machina, M. J. and W. S. Neilson. 1987. "The Ross Characterization of Risk Aversion: Strengthening and Extension." Econometrica 55 (September): 1139-49.

Markowitz, H. M. 1959. Portfolio Selection. New York: John Wiley \& Sons, Inc.

McInish, T. H. 1982. "Individual Investors and Risk-Taking." Joumal of Economic Psychology 2: 125-36.

Milne, R. D. 1983. "Determination of Portfolio Policies: Individual Investors." In J. L. Maginn and D. L. Tuttle, eds., Managing Investment Pontfolios: A Dynamic Process. New York: Warren, Gorham \& Lamont: 125-60.

Murphy, D. L., R. H. Belmaker, M. S. Buchsbaum, N. F. Martin, R. Ciaranello, and R. J. Wyatt. 1977. "Biogenic Amine Related Enzymes and Personality Variations in Normals." Psychological Medicine 7: 149-157.

Murphy, D. L., C. Wright, M. S. Buchsbaum, A. Nichols, J. L. Costa, and R. J. Wyatt. 1976. "Platelet and Plasma Amine Oxidase Activity in 680 Normals: Sex and Age Differences and Stability Over Time.” Biochemical Medicine 16: 254-65. 
Nies, A., D. S. Robinson, K. R. Lamborn, and R. P. Lambert, 1973. "Genetic Control of Platelet and Plasma Monoamine Oxidase Activity." Archives of General Psychiatry 28: 834-38.

Pratt, J. E. 1964. "Risk Aversion in the Small and Large." Econometrica 32 (January/April): 122-36.

Quattlebaum, O. M. 1987. "Investment Risk and the Individual Investor-Part II." In William G. Droms, ed., Asset Allocation for the Individual Investor. Charlottesville, VA: The Institute of Chartered Financial Analysts.

Robinson, D. S., J. M. Davis, A. Nies, C. L. Ravaris, and D. Sylvester. 1971. "Relation of Sex and Aging to Monoamine Oxidase Activity of Human Brain, Plasma and Platelets." Archives of General Psychiatry 24: 536-39.

Ross, S. A. 1981. "Some Stronger Measures of Risk Aversion in the Small and Large with Applications." Econometrica 49: 621-38.

Schooler, C., T. P. Zahn, D. L. Murphy, and M. S. Buchsbaum. 1978. "Psychological Correlates of Monoamine Oxidase in Normals." Journal of Nervous and Mental Diseases 166: 177-86.

Sharpe, W. F. 1987. "Integrated Asset Allocation." Financial Analysts Journal (September/October): 25-32.

Smith, W.L. 1982. "Microeconomic Systems as an Experimental Science." American Economic Review (December): 923-955.

Vickrey, W. 1961. "Counterspeculation, Auctions, and Competitive Sealed Tenders." Journal of Finance 16 (March): 8-37.

Walker,J. M., V.L. Smith, and J. C. Cox. 1987. "Bidding Behavior in First Price Sealed Bid Auctions: Use of Computerized-Nash Competitors." Economic Letters.

Zuckerman, M. 1979a. "Sensation Seeking and Risk Taking." In C. E. Izard, ed., Emotions in Personality and Psychopathology. Plenum Press. 
.1979b. Sensation Seeking: Beyond the Optimal Level of Arousal. Hillsdale, New Jersey: Lawrence Erlbaum Associates.

. 1984. "Sensation Seeking: A Comparative Approach to a Human Trait." The Behavioral and Brain Sciences 7: 413-71.

Zuckerman, M., J. C. Ballenger, D. C. Jimerson, D. L. Murphy, and R. M. Post. 1983. "A Correlational Test in Humans of the Biological Models of Sensation Seeking, Impulsivity, and Anxiety." In M. Zuckerman, ed., Biological Bases of Sensation Seeking, Impulsivity, and Anxiety. Hillsdale, New Jersey: Lawrence Erlbaum Associates: 22948.

Zuckerman, M., M. S. Buchsbaum, and D. L. Murphy. 1980. "Sensation Seeking and Its Biological Correlates." Psychology Bulletin 88: 187-214.

Zuckerman, M., S. Eysenck, and H. J. Eysenck. 1978. "Sensation Seeking in England and America: Cross-Cultural, Age, and Sex Comparisons." Journal of Consulting and Clinical Psychology 46: 139-49.

Zuckerman, M., T. M. Murtaugh, and J. Siegel. 1974. "Sensation Seeking and Cortical Augmenting-Reducing.” Psychophysiology 11: 535-42. 